\title{
VI. BIBLIOGRAFÍA
}

Sección coordinada por F. MARIÑo (Derecho Internacional Público), G. Palao (Derecho Internacional Privado) y C. GaRCÍA (Relaciones Internacionales)

\section{A) RECENSIONES}

\section{Álvarez Rubio, J. J.; Agogués MendizÁBal, C.; Iruretagoiena Agirrezabala- Ga, I., y Magallón Elósegui, N., Difamación y protección de los derechos de la personalidad: ley aplicable en Europa, Cizur Menor (Navarra), Aranzadi/ Thomson Reuters, 2009, 259 pp.}

1. La aprobación del Reglamento Roma II (Reglamento (CE) núm. $864 / 2007$, sobre ley aplicable a las obligaciones extracontractuales) constituye uno de los hitos recientes más destacables, en el proceso de desarrollo y consolidación de un espacio europeo en el ámbito de justicia en materia civil. Con el mencionado instrumento se culmina un muy largo proceso legislativo y se cubre una significativa laguna normativa. Asimismo, su importancia es tal que se podría decir que, junto a los Reglamentos Bruselas I y Roma I, constituyen el «núcleo duro» del sistema europeo de Derecho internacional privado. El resultado alcanzado con el Reglamento Roma II, sin embargo, no ha sido del todo satisfactorio. En este sentido, aunque resulta común aplaudir el hecho de que finalmente se aprobara el mismo, también se ha extendido la idea de que el texto aprobado es merecedor de ciertas críticas. En otras palabras y de forma resumida, puede que el Reglamento Roma II cuente con el mejor de los articulados que podían haberse alcanzado (dadas las circunstancias), pero desde luego muestra ciertas carencias que deslucen el resultado finalmente logrado.

Una de las carencias más significativa del Reglamento Roma II se manifiesta precisamente en la materia abordada en este libro. De ahí que, ya desde un inicio, haya de saludarse muy positivamente su publicación. Y ello, porque a tenor de lo dispuesto en su propio art. 1.2 se excluye de su ámbito de aplicación, en particular, «g) las obligaciones extracontractuales que se deriven de la violación de la intimidad o de los derechos relacionados con la personalidad; en particular, la difamación». Una exclusión sobradamente conocida que se vio justificada por la falta de acuerdo entre las instituciones comunitarias (subyaciendo, además, las presiones del lobby de la prensa). Pero que, al margen de las cuestiones puramente políticas, su eliminación del articulado final (dado que en propuestas anteriores sí que contaba con un tratamiento especializado) resulta especialmente censurable por varios motivos. 
Por un lado, porque se trata de un tipo de ilícito civil que van a contar con un carácter internacional en numerosas ocasiones. De tal modo que, desde un punto de vista puramente práctico, hubiera resultado conveniente su inclusión en un instrumento comunitario uniforme (a su vez, ya existían normas especializadas en la materia en el panorama comparado europeo que podrán haber servido de modelo). Por otro lado, porque desde la Sentencia del Tribunal de Justicia de la Comunidad Europea en el asunto Shevill, no cabe duda de que este tipo de situaciones de responsabilidad civil extracontractual se encuentra cubierto por el Reglamento Bruselas I. En definitiva, se trata de unos supuestos que aunque van a ser tratados de manera uniforme desde la perspectiva de la competencia judicial internacional, la disparidad seguirá siendo la tónica en el plano conflictual. Un resultado que, en modo alguno, se alinea adecuadamente con los propios objetivos del Reglamento Roma II; fomentando el forum shopping y la falta de seguridad jurídica.

2. En este complejo y poco deseable caldo de cultivo se ha de situar el art. 30 del Reglamento Roma II (cláusula de revisión); estableciéndose en su apartado 2 que: "A más tardar el 31 de diciembre de 2008, la Comisión presentará al Parlamento Europeo, al Consejo y al Comité Económico y Social Europeo un estudio sobre la situación en el ámbito de la ley aplicable a las obligaciones extracontractuales derivadas de la violación de la intimidad y de los derechos relacionados con la personalidad, teniendo en cuenta las normas sobre la libertad de prensa y la libertad de expresión en los medios de comunicación, y las cuestiones sobre conflicto de ley relacionadas con la Directiva 95/46/CE del Parlamento Europeo y del Consejo, de 24 de octubre de 1995, relativa a la protección de las personas físicas en lo que respecta al tratamiento de datos personales y a la libre circulación de estos datos». Es a este mandato al que responde el libro reseñado, subrayándo- se de este modo su gran interés, tanto teórico como práctico.

Por lo que hace a la estructura de esta obra, la misma se divide en cuatro capítulos que van llevando al lector desde la situación normativa en la que se sitúa la ordenación de los casos de responsabilidad civil derivada de la violación de derechos de personalidad en Europa, hasta elaborar valientes propuesta de futuro en vistas a superar la actual situación. En el capítulo I se ofrece al lector de un análisis comparado de la protección material de los derechos de personalidad en los Estados miembros la Unión Europa. En el II, por su parte, se enfrenta al tratamiento que han recibido estos supuestos desde el ámbito de las instituciones comunitarias. A continuación el capítulo III se dispone un estudio comparativo de las respuestas contenidas en los distintos sistemas autónomos de Derecho internacional privado, por lo que hace a la determinación de la ley aplicable. El estudio finaliza, en su capítulo IV, con una descripción de la situación actual y, de modo más significativo, con la elaboración de una propuesta reguladora de futuro.

De esta manera el estudio comienza en su capítulo I, por poner de manifiesto el motivo por el que existen tantos problemas en que la materia analizada pueda, en la actualidad, contar con un tratamiento conflictual uniforme: las grandes diferencias existentes en el equilibrio que los ordenamientos estatales otorgan a los derechos de la personalidad, de un lado, y a la libertad de expresión, de otro. Una divergencia que afecta a la distinta protección constitucional que se otorga a tales derechos al igual que su tratamiento por el Derecho civil; y que, a su vez, se encuentran en el fondo de las serias dificultades que han de enfrentarse con vistas a su ordenación en el ámbito europeo. Todo ello, a través de un completo estudio de los sistemas nacionales en la materia, así como del análisis de la jurisprudencia del Tribunal Europeo de Derechos Humanos. 
3. Tras este análisis comparado, el capítulo II se enfrenta al proceso de aproximación legislativa llevado a cabo al son de la Unión Europea. En el mismo se pone el acento, en primer término, en la dicotomía que ha existido entre la armonización sustantiva y la aproximación conflictual en el sector de la responsabilidad civil extracontractual. Y ello para, en segundo término, aproximarse al tratamiento que este tipo de ilícitos ha tenido desde el Derecho internacional privado europeo. Una aproximación en las que se destacan dos momentos singularmente decisivos: Sentencia del Tribunal de Justicia de la Comunidad Europea en el asunto Shevill y la exclusión que se hace en el Reglamento Roma II de este tipo de ilícitos civiles. Una eliminación que, en último extremo, nos aboca al capítulo III; en donde se estudian las distintas soluciones existentes actualmente en los sistemas autónomos de Derecho internacional privado, en materia de ley aplicable.

La presentación de las diferentes respuestas estatales se nos presenta como especialmente útil, para apreciar en su totalidad, las dificultades que entraña la unificación de las normas de conflicto de leyes en esta materia. Un análisis comparado que, asimismo, resulta singularmente interesante por el modo sistemático en el que ofrece al lector los resultados de esta evaluación comparativa. En esta línea, junto al estudio que hace de la importancia que posee la tradicional solución territorial lex loci delicti commissi, destaca la presentación que realiza del proceso de especialización y materialización de esta regla en la materia abordada, así como las excepciones que la regla de base encuentra en los distintos sistemas internos. $\mathrm{Al}$ respecto resulta curioso contemplar como la tradicional regla de la «double actionability» presente en algunos sistemas del Common Law, se ha convertido en una regla especial para esta materia en Inglaterra y Escocia. Y ello, al haber sido desplazada para un gran nú- mero de supuestos de responsabilidad civil extracontractual (a excepción de para los supuestos analizados) tras la reforma de sus sistemas de Derecho internacional privado en 1995.

4. La valía del estudio reseñado se pone de manifiesto en su capítulo IV. En el cual, tras ofrecer al lector una acertada descripción de los problemas a los que se enfrenta la eventual unificación de las normas de conflicto en la materia (en especial cuando analiza la posición de la industria de la comunicación), desgrana una elaborada propuesta de futuro. Así, de entre las distintas alternativas existentes, los autores se decantan por llevar a cabo una acción normativa que podría denominarse de compromiso; según la cual se sugiere que se elabore una Directiva que aborde esta temática, con el objetivo doble de que contenga un ordenación material armonizada común para los Estados miembros, a la que se añadiría una norma de delimitación de su ámbito de aplicación territorial. Siguiendo así el ejemplo de otras materias como el Derecho del consumo o la radiodifusión a través de satélite. Una propuesta que cuenta con un gran interés y que podría ser estimada como una alternativa válida, en vistas a desbloquear la situación vigente. Así, si bien es cierto que sería preferible contar con una norma de conflicto uniforme que se incorporaría como regla especial en el Reglamento Roma II, las divergencias y circunstancias existentes hacen que sea difícil poder empezar en ello.

5. En definitiva, la obra reseñada responde con valentía al envite que realiza el propio art. 30.2 del Reglamento Roma II, ofreciendo un exhaustivo análisis de la situación normativa existente en nuestros días, así como presentando valiosas propuestas normativas de futuro que buscan desbloquear el actual impasse. Por ello, se trata de un estudio de un gran valor que, sin lugar a dudas, habría de ser tomado en consideración por parte de las instituciones comunita- 
rias y, de esta manera, superar la indeseable situación en la que se encuentra la ordenación actual de los supuestos internacionales de responsabilidad civil por los atentados cometidos frente a los derechos de la personalidad en la Unión Europea.

Badía Martí, A.; Pigrau Solé, A., y Olesti Rayo, A. (coords.), Homenaje a la profesora Victoria Abellán Honrubia. El Derecho internacional ante los retos de nuestro tiempo. Dos vols. I. El Derecho internacional ante los retos de nuestro tiempo. II. La Unión Europea ante los retos de nuestro tiempo, Madrid, Barcelona, Buenos Aires, Marcial Pons, 2009.

Estos dos volúmenes constituyen el Homenaje que sus múltiples discípulos, colegas y amigos de la academia otorgan a la doctora Victoria Abellán Honrubia, maestra de toda una generación de iusinternacionalistas que, desde su Cátedra de la Universidad de Barcelona, ha ejercido sus tareas durante largos años con rigurosa y ejemplar dedicación. En la lógica de la amplia labor científica y magistral de la homenajeada los trabajos se reúnen un volumen sobre Derecho internacional propiamente dicho y otro sobre la Unión Europa y su orden jurídico.

Entre ambos volúmenes un total de 54 colaboraciones son presentadas (30 en el primero y 24 en el segundo), 23 provenientes de profesores de casi todas las Universidades de Cataluña y 31 de prácticamente todas las Universidades importantes de España. La intención evidente de elaborar un Homenaje con las colaboraciones de Universidades y académicos españoles constituye a mi juicio un rasgo destacable de estos dos volúmenes: la edición difícilmente hubiera costeado un tercer y cuarto volúmenes que incluyera las aportaciones de los múltiples colegas que fuera de España conocen y respetan la labor de la profesora Abellán: jtal es la penuria de fondos para la edición de estos Homenajes! Pero yo mismo no descarto la edición de por lo menos un tercer volumen con los trabajos de los académicos extranjeros que quieran unirse a este homenaje.
Dentro del primer volumen quisiera destacar la presencia de tres colaboraciones de profesores pertenecientes a la anterior generación a la de la homenajeada, de los que ella aprendió en su día. El tiempo devora a sus hijos y seguramente la aportación del ya fallecido D. Manuel Díez de Velasco, quien consideraba con justicia a la doctora Abellán su primera discípula, es una de las últimas sino la última que escribió: «El Derecho internacional humanitario y su relación con las minas antipersonal y las municiones de racimo", trabajo en el que analiza la Convención, adoptada en 2008, que prohíbe tales armas, convención ya incorporada al ordenamiento español; un nuevo instrumento de Derecho humanitario orientado, señala el autor, aludiendo así de modo tácito a una de sus preocupaciones personales y de jurista, a «prevenir el sufrimiento humano».

En segundo lugar el doctor Juan Antonio Carrillo Salcedo, quien colabora con su trabajo «¿Reforma de las Naciones Unidas o aplicación del espíritu y la letra de la Carta?». Nadie entre los internacionalistas españoles de su generación presentó con mayor énfasis las exigencias de justicia global y la función del Derecho internacional y la «Organización Mundial» (como la denominó en su día M. Virally) en su búsqueda y «logro»; y ello incluso antes de que la globalidad apareciera como el horizonte social, económico y político de la actual Sociedad 
Internacional (no confundir con la $\mathrm{Co}$ munidad Internacional). Los trabajos de la doctora Abellán sobre la ONU permanecen aún entre los mejores de la doctrina española.

Dentro de este ámbito material, destacaré que en el examen de los problemas de la "globalización» inciden dos destacadas colaboraciones: la del profesor J. M. Faramiñán Gilbert, de amplio aliento teórico ( «Luces y sombras de la globalización») y la del profesor X. Fernández Pons («El Derecho internacional público ante el "trilema" de la globalización») concibiéndose el "trilema» sobre la base de los tres elementos de: preservar la soberanía económica de los Estados, impulsar la cooperación internacional para la liberalización económica de los flujos económicos transfronterizos e impulsar la cooperación internacional para promover un desarrollo social y sostenible. Además, con la solvencia y escrupulosidad que le caracteriza, el profesor J. Roldán Barbero desarrolla en amplios análisis un tema bien querido por la homenajeada: «El Derecho internacional del desarrollo: un panorama actual».

En tercer lugar, el oportuno trabajo del profesor José Antonio Pastor Ridruejo, denominado « ¿Contradicciones en la práctica y jurisprudencia internacional sobre la prohibición de portar el velo islámico?». El autor, antiguo juez del Tribunal Europeo de Derechos Humanos defiende en términos bien convincentes la doctrina que sobre la prohibición por Turquía del velo islámico en los recintos universitario establece el TEDH en su sentencia pronunciada por la Gran Sala en el caso Leila Sahin c. Turquía de 1 de noviembre de 2005. La doctrina del margen de apreciación permite avalar la conformidad de dicha prohibición con la Convención de Roma de 1950 y ésa es también la posición del autor.

Destacado lo anterior, sólo es posible dejar constancia aquí del tenor general de las demás colaboraciones y quizá de algún rasgo especialmente relevante de las mismas. Algunas de ellas provienen de académicos de la misma generación que la homenajeada, pero los más son de otras generaciones sucesivas. La preocupación vital de la doctora Abellán por el respeto y la protección de los derechos humanos ha incitado sin duda a la presentación de numerosos trabajos sobre tales cuestiones. Sobre ellas se presentan hasta 12 colaboraciones. Dos están relacionadas con los problemas planteados por las exigencias derivadas para la protección de los derechos humanos de la acción antiterrorista: el del profesor Jordi Bonet Pérez («El Tribunal Europeo de Derechos Humanos y las medidas antiterroristas: entre la excepcionalidad y la especialidad normativa») y el de la profesora Nila Torres («Derechos humanos y terrorismo, detenciones ilegales y "Vuelos secretos" »); y otro sobre Derecho humanitario, entregado por el maestro Manuel Pérez González: «El art. 3 común a los convenios de Ginebra de 1949 como expresión normativa del "poder de la $\mathrm{Hu}$ manidad": algunas reflexiones».

Otros trabajos abordan estas cuestiones: el profesor Carlos Fernández de Casadevante escribe sobre «El estatuto de las víctimas en Derecho internacional», entendida la víctima como la que ha sufrido un daño injusto por violación del Derecho internacional; el profesor Carlos Fernández Liesa, sobre «Aspectos jurídico-humanitarios de la Guerra civil española», de elevado interés histórico; el profesor Pablo A. Fernández sobre un tema caro para él: «La positivación jurídico-internacional de los deberes del ser humano»; la profesora Cristina González Beilfuss, sobre «El reconocimiento de resoluciones judiciales extranjeras y el Convenio europeo de derechos humanos» (que estudia en qué medida el reconocimiento o la denegación de éste en un foro interno, pueden configurar una violación de la indicada Convención); el trabajo de X. Pons Rafols sobre «Biomedicina y Derecho internacional, nuevas 
fronteras de la ciencia, nuevas dimensiones de los derechos humanos» y el trabajo de Jaume Saura Estapà sobre «Noción, fundamento y viabilidad de los derechos humanos emergentes: una aproximación desde el Derecho internacional», ambos en la mejor tradición prospectiva de los análisis jurídicos.

Asimismo, el trabajo sobre un ámbito en el que es ya un maestro, del profesor Eduard Sagarra Trias, sobre «La globalización, derechos humanos y el fenómeno de la inmigración». Por último, mi propia aportación sobre el «Comentario General al art. 2 de la Convención contra la tortura», aprobado por el Comité contra la tortura de Naciones Unidas en 2007.

En relación con la protección internacional de los derechos humanos, y con la exigencia de responsabilidad penal o civil ante órganos competentes, internos o internacionales, se encuentran tres trabajos: el de la profesora Esperanza Orihuela sobre «Jurisdicción universal e inmigración: Derecho internacional y Derecho español», centrado sobre todo en la cooperación para la represión del tráfico y trata de personas; el de la profesora Helena Torroja sobre el «Concurso de delitos en el Estatuto de Roma: problemas derivados de la doble incriminación de un mismo hecho a título de crímenes contra la Humanidad y crímenes de guerra»; y en un ámbito intersistémico e interdisciplinar, con la complejidad que es siempre de su elección, el trabajo de Antonio Pigrau Solé sobre "La responsabilidad de las empresas transnacionales por daños graves al medio ambiente: explorando la vía de "Alien Tort Claims Act" ». En tema medioambiental aunque en perspectiva más interestatalmente clásica la profesora M. ${ }^{\mathrm{a}}$ Teresa Ponte escribe sobre «La contaminación de los cursos de agua internacionales y la preservación del medio marino a la luz del conflicto de las plantas de celulosa sobre el río Uruguay».

En cuanto al contenido de este primer volumen cabe aún dar cuenta de nueve colaboraciones más. Tres de ellas de clasificación singular: la del profesor José Juste sobre «Buques de Estado hundidos y protección del patrimonio cultural subacuático: el llamado "Caso Odyssey"»; la del profesor C. Díaz Barrado (en un área de la que es ya un buen especialista) sobre «La carta cultural Iberoamericana: una pieza básica para la configuración de un espacio cultural iberoamericano", y la del profesor Viñas Farré sobre «La nueva legislación andorrana en materia de sociedades mercantiles».

Sobre temas que podemos denominar de dogmática o teoría general, siempre escasos y por ello más valiosos si cabe, el profesor Cesáreo Gutiérrez Espada escribe (con la sabiduría de los años y su buen hacer en este ámbito) sobre «Los modos de hacer efectiva la responsabilidad», que es desde luego la responsabilidad internacional. El profesor David Bondía, acude con su trabajo sobre «Reflexiones teóricas sobre la progresividad en la imposición de sanciones por parte del Consejo de Seguridad, en el que la oportuna solución de la tensión entre licitud y legitimidad de las decisiones sancionatorias del Consejo, en un marco de progresividades sometidas al Derecho internacional general y a la Carta, da la clave de la adecuación de los medios a los fines. Por su parte, el profesor Albert Galinsoga escribe sobre "El concepto de soberanía en el Derecho internacional actual», noción cuyo análisis se sitúa frente al alto y noble horizonte de la humanización del Derecho internacional. Más limitados en su ámbito material pero de amplia relevancia, histórica y actual son el trabajo de la profesora Anna Badía sobre «La cuestión del Sahara occidental y la explotación de sus recursos naturales» (la propia doctora Abellán es maestra en cuanto se refiere al principio de libre determinación) y el del profesor Antonio F. Fernández Tomás «El principio de la soberanía permanente sobre las riquezas y recursos naturales: entre la invocación retórica y la inaplicación judicial», que 
continúa brillantemente sus análisis previos. Y en este lugar, es pertinente engranar por su tema el trabajo de Luis Miguel Hinojosa Martínez: «A favor del análisis económico del Derecho internacional y de la renovación metodológica», de gran interés como proveniente de los trabajos en la materia de la escuela iusinternacionalista granadina, incluso para un jurista como yo más preocupado por discutir ante todo sobre las reglas sociales y su valor jurídico sensu stricto.

El volumen segundo dedicado a la Unión Europea, presta homenaje a la obra dedicada por la profesora Abellán, durante toda su vida académica, al fenómeno jurídico y político de la integración europea, ya desde su misma tesis doctoral. La persistencia ilimitada de la propia Unión Europea, en sí misma considerada, o desde el ángulo de la irreversible pertenencia a ella de un Estado determinado, es examinada por el profesor José Martín y Pérez de Nanclares, teniendo en cuenta la posibilidad de retirada regulada ahora desde la adopción del Tratado de Lisboa, en su trabajo: «La duración ilimitada de la Unión Europea: ¿Voluntad jurídica o realidad jurídica?».

Varios trabajos abordan cuestiones referentes a la protección de los derechos humanos en y por la Unión Europea. Así, los profesores J. Liñán Nogueras y Pablo J. Martín Rodríguez escriben su colaboración sobre «Reflexiones sobre los derechos fundamentales en la Unión Europea a la luz del Tratado de Lisboa», y Andreu Olesti, sobre «La cooperación al desarrollo de la Unión Europea y el respeto de los derechos humanos». Más en relación con Derecho material de los derechos humanos, fruto de la cooperación internacional, "La trata de seres humanos en el Derecho de la Unión Europea», es el objeto del trabajo de Marta Gómez Ortega. Por otro lado, puede considerarse que el trabajo de la profesora Esther Barbé sobre «Normas vs. Incentivos: el caso del diálogo político y de la resolución de conflictos en la "Europa más amplia"», cum- ple el papel dentro del volumen de un trabajo general sobre la acción exterior de la Unión Europea. Pero aparte de éste, el volumen incluye dos trabajos en los que se examinan los más concretos problemas de la acción antiterrorista (como política de la Comunidad Internacional y como elemento de la lucha contra la criminalidad internacionalmente organizada): Joaquim J. Forner escribe sobre la eficacia en el ordenamiento de la Unión de actos "antiterroristas» del Consejo de Seguridad de Naciones Unidas, en su trabajo: «Las señoras Möllendorf topan con los talibanes»; y la profesora Nicole Stoffel Vallotton, lo hace largamente, sobre "¿Hacia una política euro mediterránea de seguridad? El "Código de conducta" del proceso de Barcelona (Unión para el Mediterráneo) y el marco de cooperación actual en la lucha contra el terrorismo internacional en esta región». Además se examinan ciertos aspectos de la política exterior y de seguridad común por el profesor Alberto Herrero de la Fuente en: «Algunas consideraciones sobre la política exterior y de seguridad común de la Unión Europea tras la firma del tratado de Lisboa»; y de la política de seguridad y defensa por la profesora Milagros Álvarez en su trabajo "Límites y condicionantes de la política de seguridad y defensa de la Unión Europea».

Varios trabajos analizan aspectos institucionales de la Unión: la profesora Huici Sancho examina (con pesimismo) las tensiones derivadas de la participación de las regiones en: «Las regiones con competencias legislativas en el Comité de las regiones: los encuentros y desencuentros continúan»; Manuel López Escudero analiza extensamente, con su magnífico estilo, las cuestiones sempiternas de «La financiación de la Unión Europea: reflexiones sobre una reforma necesaria»; por su parte Mercedes de Solá i Domingo examina la «Prevención y resolución de conflictos en la política de personal de la Comisión Europea: nuevas tendencias». Más en concreto dos de nuestros mejo- 
res «iusinternacionalistas/comunitaristas» examinan cuestiones generales relacionadas con el Tribunal de Justicia: la profesora Lucía Millán Moro, sobre «Las competencias constitucionales del Tribunal de Justicia de las Comunidades Europeas» y el profesor José Manuel Sobrino Heredia sobre «La actividad consultiva del Tribunal de Justicia de las Comunidades Europeas».

Sobre políticas comunitarias «materiales» presentan trabajos el profesor Rafael Casado Raigón, en torno a «La aplicación de la política pesquera común en el mar Mediterráneo»; los profesores A. del Valle Gálvez y Miguel A. Acosta Sánchez sobre "Asilo y refugio en la Unión Europea: evolución y tendencias»; la doctora Mar Campins Eritja sobre «Las medidas de vigilancia y control epidemiológico en la Unión Europea»; y, desde una visión más extracomunitaria, el profesor A. Remiro Brotóns sobre «La incidencia del Derecho comunitario en materia de patentes». Y, last but not least, el trabajo de la profesora y compañera académica de la homenajeada, Alegría Borrás Rodríguez sobre «La falta de unificación del ámbito de aplicación del Derecho internacional privado comunitario».

Por último, sobre el orden jurídico de la Unión, como sistema de normas jurídicas, y sus elementos, varios trabajos se integran en el volumen. El escrito por la profesora Paz Andrés Sáenz de Santamaría sobre «Los actos comunitarios atípicos y su incidencia en la legislación española»; el de F. Jesús Carrera Hernández sobre «Réquiem por las decisiones marco, a propósito de la orden de detención europea»; el de la profesora Araceli Mangas Martín en torno a «Reflexiones sobre el sistema de actos legislativos y no legislativos en el non nato tratado constitucional»; el del ex eurodiputado Manuel Medina Ortega sobre «Los instrumentos de Derecho indicativo en la Unión Europea» y el de Miquel Palomares Amat sobre «Las normas secundarias como manifestación de la autonomía del Derecho de la Unión Europea».

Pocos recuerdan que la profesora Abellán ha sido la primera catedrática española de Derecho internacional público, considerado como disciplina académica autónoma. Pero entre sus virtudes personales está la modestia y sé que no le da importancia ni a ello ni al ejemplo, tan vigoroso y legítimo, de su síntesis personal entre teoría y práctica del Derecho internacional, siempre en la vanguardia en defensa de los valores de la paz, la democracia, el Estado de Derecho y los derechos fundamentales. Vaya pues, con esta breve recensión, mi tributo a su amistad ya de más de cuarenta años.

Fernando M. MARIÑo MENÉNDEZ Universidad Carlos III

\section{Basedow, J.; Birds, J.; Clarke, M.; Cousy, H., y Heiss, H. (eds.), Principles of European Insurance Contract Law, München, Sellier, 2009, 668 pp.}

1. Los estudios consagrados al «Derecho privado europeo» otorgan un interés marginal a los logros alcanzados en materia de contrato de seguro. Un sector de indudable importancia práctica que encuentra en esta obra un referente de primer orden. Los «Principios de Derecho Europeo del Contrato de Seguro» (en adelante PEICL) son fruto de la labor desarrollada por el grupo de investigación
Restatement of European Insurance Contract Law (http://www.restatement.info/). El citado grupo está compuesto por 21 profesores provenientes de diferentes países de la Unión Europea y Suiza. Esta pluralidad en la configuración del grupo intenta garantizar que durante la elaboración de sus trabajos participen activamente profesores formados en los diferentes modelos regulatorios que sobre 
contrato de seguro existen en el Espacio Económico Europeo.

Su fundador fue el profesor ReichertFacilides, quien recogió los argumentos esgrimidos en el Congreso de Basilea de 1998 sobre la conveniencia de reactivar el proceso de unificación de la regulación sobre contrato de seguro en la Unión Europea. Efectivamente, tras los significativos avances que se habían producido tanto en la normativa sobre ordenación y supervisión de entidades aseguradoras, como incluso en sede de mediación, parecía inexcusable acometer nuevos esfuerzos en sede contractual que trataran de conciliar las diferentes regulaciones que sobre contrato de seguro se dan en el seno de la Unión Europea, incluyendo a su vez a Suiza por la innegable influencia de sus entidades aseguradoras y reaseguradoras.

El grupo adoptó como método de trabajo el modelo de los «Restatments» americanos. Esta metodología había sido ya probada con éxito en Europa por la denominada Comisión Lando que había alumbrado sus «Principios de Derecho contractual Europeo» (los conocidos como PECL). Recordemos que "Restatement» proviene del verbo «restate», el cual puede ser traducido como «expresar de nuevo o de un modo diferente, especialmente de forma más clara o convincente». En la esfera jurídica "Restatement» es un término técnico que proviene de los Estados Unidos de América, para describir un cuerpo que condensa reglas jurídicas provenientes de diferentes pero similares fuentes, sistematizadas y unificadas en el sentido de una «mejor solución».

Posteriormente, la Comisión Europea a través de las comunicaciones de 2003 y 2004 [Comunicación de la Comisión al Consejo y al Parlamento Europea sobre un Derecho contractual europeo más coherente: un plan de acción, 12 de febrero de 2003, COM (2003) 68 final; y la Comunicación de la Comisión al Consejo y al Parlamento sobre un Derecho con- tractual europeo y la revisión del acervo comunitario: perspectivas para el futuro, 11 de octubre de 2004, COM (2004), 651 final] acogió la idea de desarrollar un Marco común de Referencia para el Derecho contractual europeo, incorporándose el grupo Restatement of European Insurance Contract Law a la red de excelencia que surgió con tal finalidad ( $w w w$. copecl.org).

2. Por lo que hace al contenido de la obra, los PEICL están divididos en tres grandes partes. El libro comienza con un capítulo introductorio donde, además de señalar los principales hitos en la elaboración del trabajo, explica cuáles han sido las grandes opciones conceptuales que se han seguido en la configuración de los PEICL. La segunda parte, la de mayor extensión, está dedicada a las reglas, que van acompañadas - siguiendo el ya mencionado estilo de los Restatementde unos comentarios que facilitan su interpretación y por ende su aplicación, y de unas notas donde se condensa el estado de la cuestión en las diferentes legislaciones europeas, como punto de partida y contraste de la regla alcanzada por el grupo. Por tanto, y ésta es una de las grandes aportaciones de la obra ahora recensionada, nos encontramos con un potente instrumento de Derecho comparado, pues sus notas contienen una rigurosa síntesis de la aproximación que realizan los ordenamientos jurídicos de la Unión Europea y Suiza a los diferentes tópicos que plantea el contrato de seguro. El origen académico de la obra, queda así patente.

La tercera parte de los PEICL recoge diferentes traducciones efectuadas de la versión oficial. Efectivamente, el texto ha sido redactado en inglés, aunque la terminología utilizada no haya sido la propia del Derecho anglosajón, pues como se advierte, la intención de los redactores ha sido acoger una terminología lo más internacional posible. No obstante, se han recopilado una serie de traducciones, únicamente de las reglas, a diferen- 
tes idiomas (se incluye una en español) que permiten la lectura de la parte más sustancial de la obra a quienes no estén familiarizados con el inglés.

El ámbito de aplicación de las reglas se extiende a cualquier contrato de seguro, excepto los reaseguros (art. 1:101). En cuanto a los riesgos especiales (p. ej., seguro marítimo), quedan comprendidos dentro de su ámbito, si bien aquí el régimen es completamente dispositivo (art. 1:103). Una mención especial merece el art. 1:103, pues es el destinado a regular el carácter imperativo de sus reglas, distinguiendo tres tipos de situaciones. En primer lugar, hay determinados artículos, los menos, que son absolutamente imperativos, no pudiendo ser derogados por ninguna de las partes. En segundo lugar, al igual que hace la legislación española en armonía con la mayor parte de las regulaciones europeas, se establece la naturaleza semiimperativa del resto de sus mandatos - la práctica totalidad-, por lo que cabe la modificación de sus disposiciones solo cuando el resultado sea más beneficioso para el tomador, asegurado o beneficiario. Se garantiza por esta vía un elevado nivel de protección a la parte débil del contrato de seguro. Finalmente, se establece el carácter dispositivo del conjunto de la regulación para determinados seguros, en sintonía con las Directivas comunitarias que introdujeron el concepto de grandes riesgos.

3. Pese al volumen de la obra, los PEICL solo alcanzan en esta edición a las disposiciones generales, divididas en trece capítulos, pero sin ocuparse de ningún seguro en particular. Las reglas se dividen así en tres grandes partes: la primera, dedicada a las cuestiones generales; la segunda, a los seguros indemnizatorios; y la tercera, se ocupa de los seguros de sumas. Consiguientemente, se ofrecen disposiciones generales aplicables a cada una de estas modalidades, tras una primera amplia sección dedicada a las disposiciones generales aplicables a cualquier contrato de seguro. Por tanto, los PEICL acogen como summa divisio del contrato de seguro la dicotomía entre seguros de indemnización y de suma. Se apartan así de aquellas legislaciones, como la española, en que la disquisición se hace en torno a seguros de daños y seguros de personas, con el trasfondo dogmático que ambas opciones acarrean.

Helmut Heiss, autor del capítulo introductorio, plantea aquí el debate sobre la utilización de los PEICL como instrumento opcional, el cual se caracteriza porque su aplicación depende de la voluntad de las partes del contrato. No se trata de ofrecer una regulación que sustituya al Derecho nacional del contrato de seguro, sino de proporcionar una alternativa que se configuraría como una nueva regulación diferenciada de las ya existentes en los países miembros de la Unión Europea. De este modo, la adopción de los PEICL haría posible que las entidades aseguradoras proporcionasen sus servicios en todo el mercado interior, basándose en normas uniformes que establecen un elevado estándar de protección para el tomador del seguro y, por otro lado, los ciudadanos europeos tendrían acceso a productos aseguradores extranjeros.

4. La singularidad de la obra hace compleja la labor de quien recensiona a la hora de dar cuenta de su contenido. Muchas son las reglas ofrecidas, por lo que sintetizar de forma exhaustiva todas ellas resultaría excesivamente prolijo. No obstante, puede ser clarificador para el lector resaltar algunos artículos que pueden llamar la atención desde la óptica del Derecho español. Comenzaremos señalando la admisibilidad de medidas preventivas, que permiten al asegurador establecer cláusulas que exijan un comportamiento por parte del asegurado antes de que acontezca el siniestro, llegando incluso a privarle de la indemnización, siempre y cuando la cláusula cumpla los requisitos contenidos en el art. 4:103.

Un tinte protector del tomador tiene el art. 2:202 PEICL, donde se contiene el 
deber del asegurador de advertir las inconsistencias que aprecie en la cobertura. Efectivamente, según prevé el citado precepto, en el momento de formalizar el contrato, el asegurador deberá advertir al solicitante de cualquier inconsistencia entre la cobertura ofrecida y las necesidades del solicitante que sean o debieran ser conocidas por el asegurador, considerando las circunstancias y la forma de contratación y, en particular, si el solicitante estuvo asistido por un mediador independiente. En caso de incumplimiento del deber o bien el asegurador indemnizará al tomador del seguro de cualquier pérdida resultante del incumplimiento del deber de advertencia, a menos que el asegurador hubiera actuado sin culpa; o bien el tomador del seguro podrá terminar el contrato mediante comunicación escrita dentro de los dos meses siguientes a que el incumplimiento sea conocido por el tomador del seguro. Otro ejemplo de precepto que se separa del prisma español puede encontrarse en el art. 5:104, donde se reconoce expresamente el principio de divisibilidad de la prima. Éste obliga a las aseguradoras a retornar la prima en caso de finalización anticipada del contrato. Se acoge así justo el principio contrario al proclamado en Espa- ña, aunque conviene advertir, como se señala en sus notas, que la divisibilidad es la regla general en los diferentes ordenamientos jurídicos que han inspirado los PEICL.

En fin, se efectúa en el art. 6:105 una aproximación interesante a la problemática sobre la demora del asegurador en el cumplimiento de su prestación. Aquí se establece, en primer lugar, que si no se satisface la indemnización, el reclamante tendrá derecho al cobro de intereses sobre esa suma, desde el momento en que fuera pagadera hasta el momento efectivo del pago, y el interés será igual al aplicado por el Banco Central Europeo a su más reciente operación principal de refinanciación efectuada antes del primer día natural del semestre en cuestión, más siete puntos porcentuales, alineándose así con la Directiva 2000/35/CE. Sin embargo, este régimen, que dulcificaría en gran medida el vigente en España, se aquilata al admitir el derecho del reclamante a que se cubran los daños por las pérdidas adicionales ocasionadas por la demora en el pago de la indemnización.

$$
\begin{array}{r}
\text { Guillermo Palao MoReno } \\
\text { Universidad de Valencia }
\end{array}
$$

\section{Cebada Romero, A., La Unión Europea: ¿Una acción exterior inteligente?, Ma- drid, Iustel, 2008 (con prólogo de F. Mariño Menéndez).}

Plantear la inteligencia o falta de inteligencia de la acción exterior de la Unión Europea es adentrarse en un terreno inexplorado y prácticamente virgen, en el cual las arenas movedizas aparecen con frecuencia. Y, sin embargo, el arrojo de la profesora Cebada Romero se ve coronado por un indudable éxito, alcanzado no sin sortear previamente abundantes dificultades.

La personalidad o subjetividad internacional de la UE se ha ido construyendo poco a poco hasta llegar al vigente Tratado de Lisboa. Es más, durante la vigencia de los Tratados de Ámsterdam y Niza, la personalidad internacional de la UE era como mínimo cuestionada por un importante sector doctrinal; hoy esta personalidad se ha concretado en el Alto Representante de la Unión para Asuntos Exteriores y Política de Seguridad.

Teniendo presente la multidimensionalidad de la acción exterior europea, la autora señala con acierto que ésta «es también una de las vías a través de las cuales se define la identidad europea» (p. 19). Sin duda estamos ante un aspecto esencial para el presente y el futuro de 
la Unión, aunque la mayoría de la doctrina lo eluda con gran frecuencia e incluso recele de quienes se atreven a abordarlo.

La obra parte del concepto de Organización Internacional, superada ya la estéril querella de si el Tratado por el que se establecía una Constitución para Europa tenía naturaleza convencional o constitucional (querella que por cierto no fue alimentada desde los internacionalistas). Obviamente la UE es un proceso de integración regional, abierto a los Estados europeos, que además desarrolla la «inclusividad» respecto a los terceros Estados o terceras Organizaciones Internacionales. Podemos hablar así de una inclusividad exterior (con una clara orientación solidaria) que explica en parte una acción exterior de la UE que hoy no puede ser sino planetaria.

En las relaciones entre el Derecho internacional público y el Derecho de la UE (tras la entrada en vigor del Tratado de Lisboa parece difícil seguir hablando con exactitud de «Derecho comunitario», cuando la Comunidad Europea ha desaparecido, salvo la de Energía Atómica) puede hablarse hoy —como hace la autora- de "un régimen autocontenido». Pero la Unión, como cualquier otro sujeto del ordenamiento internacional, debe en todo caso respetar las obligaciones internacionalmente asumidas, especialmente las derivadas de las normas ius cogens; ese respeto se ve facilitado por el carácter dispositivo de numerosas normas internacionales en la que podemos denominar la teoría general de las Organizaciones Internacionales. Es necesario destacar esta caracterización de la Unión, para no mezclar confusamente las aguas de lo jurídico y lo político. En esta misma óptica, habrá que recordar que desde luego no nos encontramos en la actualidad en la Europa postestatal (a pesar de algunas teorías de finales del siglo pasado, enseguida superadas por la evolución de la UE).

La relevancia internacional de la UE se diferencia de la superpotencia, sobre todo en cuanto la Unión no pretende emular el poder de nadie ni situarse por encima de nadie. Afortunadamente este poder civil de la Unión (en ocasiones no tan blando como a simple vista pudiera parecer) no se presenta como un poder excluyente, puesto que «la voluntad de los otros importa» (p. 83).

Después de trazar los parámetros generales, la autora se adentra en los terrenos concretos, en los temas esenciales de la gestión de las crisis, la promoción del regionalismo, la cooperación para el desarrollo, la promoción de los Derechos Humanos, la Democracia y el Estado de Derecho, la proyección del principio de solidaridad en la acción exterior y, en último lugar, en la inmigración y el asilo. En todos los terrenos enunciados, desde una posición crítica, esta obra subraya las carencias y a veces hasta incoherencias de la acción exterior.

La gestión de las crisis no puede abordarse sin tener presentes las deficiencias o carencias de la UE en el terreno militar. Desde la derrota en 1954 en la Asamblea Nacional francesa del Tratado por el que se creaba una Comunidad Europea de Defensa, la debilidad militar de la Unión ha sido terreno abonado para que estuviera permanentemente endeudada al poder de Estados Unidos, directa o indirectamente vía OTAN. Todo ello no significa que la gestión de las crisis no haya sido progresivamente reforzada y mejorada, pero al faltar esta mínima coherencia militar intra-Unión, la efectividad en su acción exterior decae y se ve sometida a los vaivenes del mayor o menor entendimiento entre sus principales Estados miembros; el ejemplo de la desaparición de la antigua Yugoslavia (sobre el cual la UE tal vez no haya realizado la correspondiente autocrítica ni haya extraído las oportunas lecciones) lo demuestra sobradamente.

El impulso o promoción del regionalismo también constituye una tarea permanente de la UE, a pesar de que los éxi- 
tos no parecen ser demasiado patentes. Por ejemplo, las relaciones entre la UE y América Latina y el Caribe oscilan entre dicha promoción y una permanente tentación de vuelta al bilateralismo (ciertamente, en ocasiones el bilateralismo se ve acentuado por los propios Estados latinoamericanos, que todavía no perciben con claridad la imagen exterior de la UE y solicitan que ésta les trate de modo individualizado).

Un terreno donde la Unión parece cosechar éxitos es sin duda la cooperación para el desarrollo. En su tratamiento, la autora traspasa los límites del simplismo del cual a veces nos imbuyen los medios de comunicación y recuerda «el pilar comercial de la cooperación para el desarrollo» (pp. 106 y ss.)

La promoción de los Derechos Humanos, la Democracia y el Estado de Derecho (que a mi entender forman parte indisoluble de la identidad europea) permiten plantear temas tan actuales como el respeto de tales Derechos para las personas acusadas de contribuir al terrorismo, de pretender destruir los Derechos de otras personas. Destaca el protagonismo del caso Yassin Abdullah Kadi (en el cual el Tribunal de Justicia todavía no había dictado la sentencia de 3 de septiembre de 2008 cuando escribía la profesora Cebada Romero, que anula las Sentencias del Tribunal de Primera Instancia de la UE).

La proyección del principio de solidaridad en la acción exterior pretende materializar la agenda social internacional de la UE. Desde luego la UE se vale del multilateralismo, hoy generalmente profesado tras haber sido gravemente denostado en la etapa Bush. En esta proyección se produce una «sutil influencia de la UE», especialmente en Latinoamérica, mucho más en la teoría que en la práctica, puesto que existe un escaso compromiso financiero, una escasa solidaridad (p. 146).

Con una calificación que en estos momentos ha de considerarse bastante indulgente, la autora habla de la inmigración y el asilo como "campo abonado para las incoherencias» (pp. 146 y ss.). Examina sobre todo la Directiva de reagrupación familiar y sus vicisitudes procesales. Pero no se olvida ni de los acuerdos de readmisión (a cuya celebración algunos Estados se resisten firmemente) ni de la peor de las técnicas (desde los Derechos Humanos) utilizada por la UE en materia de asilo, la denominada «internacionalización del asilo»; es bien conocido que estamos ante una técnica fundamentada en la arbitraria calificación de un Estado tercero como «seguro» para el solicitante de asilo y sus Derechos Humanos (simplemente recordaremos que son calificados como «seguros» Estados «tan respetuosos de los Derechos Humanos"... como Albania, los del Cáucaso o incluso Libia).

La indulgencia de la calificación ofrecida por la autora en materia migratoria y de asilo (donde no acaba de establecerse el anunciado SECA o Sistema Europeo Común de Asilo) se explica sobre todo porque en el momento de la redacción de esta excelente monografía no se había producido la adopción de la denominada Directiva de Retorno y tampoco había sido adoptada la Directiva de sanciones a los empleadores de personas en situación irregular. A mi entender, la primera con toda justicia puede calificarse de "Directiva de la vergüenza», como demuestra especialmente la violación de los derechos procesales de los extranjeros [que pueden ser informados en una lengua que «el nacional de un tercer país comprenda o pueda suponerse razonablemente que comprende» (art. 12.2), la posibilidad de internamiento hasta 18 meses (art. 15.6), el internamiento de familias y el internamiento de menores (art. 17; en la mente del legislador europeo, seguramente esta norma debe materializar «el interés superior del menor», del que habla la Convención de Derechos del Niño, por cierto ratificada por los 27 Estados miembros de la UE)]. 
Concluye la profesora Cebada Romero con todo acierto que «el modelo de "poder inteligente" [...] no es un punto medio entre los modelos de soft o civil power, de un lado, y de hard power, por otro, sino que estaría mucho más cerca del primero que del segundo» (p. 175), conclusión que sin duda obedece a la situación actual de la UE. También resulta exacta la afirmación según la cual la UE es una actora que «está en condiciones de impulsar la evolución del ordenamiento jurídico internacional en la dirección de la construcción de un Derecho más social y más humano» (p. 176). Por otro lado destaca como esencial que la UE «se mantenga fiel a su paradigma de poder civil, aunque añadiéndole una dimensión militar [...] Tendríamos entonces una acción exterior inteligente» (p. 178).

Esperemos que la regulación de la inmigración y el asilo («cuyas normas se sitúan en el límite (quizás incluso traspasándolo) de lo que resulta admisible desde la perspectiva del Derecho internacional de los derechos humanos», como con toda razón escribe la autora, p. 175) no lleven a la UE por la senda de la discrimi- nación, del cinismo del doble o triple lenguaje, de Derechos para los ciudadanos pero no para los extranjeros en sentido propio. Si no se modifica la actual deriva normativa migratoria, la Unión estará comenzando a perder su misma identidad; lo más grave de todo ello es que la pérdida se estará produciendo con todas las bendiciones de un Parlamento que hemos elegido directamente.

No ha de considerarse como una cláusula de estilo la afirmación según la cual estamos ante una obra de lectura obligada para cuantos nos aproximamos en profundidad a la Unión Europea. Esta indispensable obra aborda la cuestión esencial de la identidad europea, a la que el Parlamento Europeo ha destinado muchos esfuerzos, por lo menos desde hace tres décadas y media. Afortunadamente esta excelente monografía sitúa dicha identidad en el firme terreno de los derechos humanos, sin los cuales no se entiende ni la integración europea ni la actual acción exterior de la UE.

Ángel Chueca Sancho
Universidad de Zaragoza

\section{Espinar Vicente, J. M., Tratado elemental de Derecho internacional privado} (Prólogo de Sixto Sánchez Lorenzo), Alcalá de Henares, Universidad de Alcalá, 2008, 725 pp.

1. Fruto de una continuada dedicación al estudio del DIPr durante más de tres décadas y media, el Tratado del profesor Espinar Vicente adquiere un especial valor como una suerte de manifiesto generacional, que refleja y actualiza la concepción del DIPr y los temas objeto de preocupación y estudio que marcaron a toda una generación clave en el desarrollo de esta disciplina en España. José María Espinar reafirma en este Tratado su convicción en el potencial de esos planteamientos en el momento actual, lo que se corresponde con que aparentemente su evolución a lo largo de tan dilatada trayectoria haya sido menos marcada que la de otros miembros de su genera- ción. Ciertamente, el libro constituye en gran medida un compendio actualizado de la vasta producción anterior del autor en los diversos sectores del DIPr y en otros conexos, si bien el resultado es un Tratado que presenta rasgos peculiares y un enfoque original que lo singularizan en el panorama actual de los tratados generales o manuales españoles de DIPr.

La excepcional transformación de España y de las relaciones privadas internacionales en las últimas décadas ha contribuido a consolidar una especie de ruptura generacional. Entre las consecuencias de esa quiebra se encuentra el que los estudiosos del DIPr que iniciaron 
su formación a partir de los años noventa del siglo xx hayan en ocasiones minusvalorado las aportaciones de la doctrina española en las décadas inmediatamente anteriores, considerando que la nueva realidad reclama enfoques diferentes lo que parece menoscabar el significado como referente de las aportaciones previas. Esta circunstancia se ha visto favorecida por el hecho de que buena parte de los autores más jóvenes hayan prestado particular atención a ámbitos del Derecho privado que habían sido objeto de un tratamiento menor o incluso habían estado huérfanos de estudio en las décadas precedentes.

Mérito indiscutible de este nuevo Tratado es que constituye un instrumento de diálogo intergeneracional y se convierte en una referencia indiscutible para apreciar la vigencia y utilidad de la metodología y los planteamientos del autor de cara al conocimiento y la aplicación del DIPr español en el momento presente. El aludido significado del Tratado como mecanismo de afirmación generacional y personal resulta avalado por las consideraciones de Sixto Sánchez Lorenzo en el Prólogo y de José Carlos Fernández Rozas en el Epílogo, que refuerzan la originalidad del libro y su carácter singular entre la reciente bibliografía española de DIPr.

2. En su estructura, el Tratado constituye un extenso volumen que aborda el conjunto de las materias que integran el contenido del DIPr, en su concepción más amplia -incluyendo la nacionalidad y la extranjería - desde una perspectiva tradicional, en la que la dimensión patrimonial y, en particular, mercantil de las relaciones privadas internacionales recibe una atención menor. Es éste un enfoque bien conocido entre los manuales españoles de DIPr, en alguno de los cuales se halla consolidado el apego a esa concepción, sin perjuicio de que el propio autor pone de relieve lo forzado de la pretensión de encajar el estudio de la nacionalidad y la extranjería en el contenido del DIPr. En todo caso, el paso del tiempo, precisamente, ha erosionado la trascendencia práctica del debate acerca de la inclusión de esos sectores del contenido del DIPr, en la medida en que el criterio de que quedan fuera de tal contenido en sentido propio no menoscaba en absoluto la importancia de esos sectores, su vinculación con el contenido del DIPr, y que los especialistas de DIPr se encuentren en una posición de privilegio para ocuparse de su estudio.

El primer núcleo de cuestiones que integran el contenido del Tratado va referido a la llamada parte general del DIPr, en concreto del sector del Derecho aplicable, con particular atención a los métodos de reglamentación del DIPr, deteniéndose el autor en el significado de la norma de conflicto como paradigma y en las claves de su aplicación, así como en los distintos tipos de normas. Los capítulos V a VII se hallan dedicados al Derecho de la nacionalidad y al régimen jurídico de la inmigración. La vertiente procesal es objeto de tratamiento en particular en los capítulos VIII — dedicado básicamente a la competencia judicial internacional-y IX, centrado en el reconocimiento y ejecución de decisiones extranjeras. De la jurisdicción voluntaria se ocupa el capítulo XI, junto con el estudio de la ley aplicable a la forma de los actos jurídicos. Por último, los capítulos XII a XVI abordan desde la dimensión del tráfico externo las diversas instituciones del Derecho civil, en particular, el matrimonio, la filiación, la adopción, los derechos reales y las obligaciones contractuales y extracontractuales.

Lo amplio y completo del contenido no impide apreciar que en su desarrollo son marginados ciertos aspectos que han merecido especial atención por la doctrina en los últimos años, como es el caso de buena parte de las instituciones de Derecho mercantil. Esta situación se coordina armónicamente con la visión del DIPr como un sector del Sistema de Derecho de carácter básicamente estatal, de la que parte el autor. A este respecto, resulta significativo que la autorregulación y la 
aplicación de normas extraestatales a las relaciones privadas internacionales desempeñan un papel especialmente relevante en el ámbito mercantil y en el marco de los mecanismos alternativos de solución de controversias con especial impacto sobre ese sector del tráfico externo.

3. Más allá de su contenido, en el panorama de las obras generales de DIPr ésta destaca por su enfoque y método. Un aspecto muy llamativo, que se compadece con la referencia en el título al carácter «elemental» de este Tratado es que el autor lleva a cabo un especial esfuerzo por situar el análisis en el nivel de los principios, de los fundamentos de los sectores del ordenamiento e instituciones analizados, así como de las posibles orientaciones de política legislativa y sus alternativas. La esencia de ese enfoque aparece expresada con toda claridad por el autor en sus primeras palabras del Tratado, que comienza con la afirmación de que su finalidad es básicamente proporcionar un método y una técnica hermenéutica para el estudio y aplicación del DIPr más que ofrecer un catálogo de soluciones para sus problemas de regulación. Este enfoque, llevado hasta sus últimas consecuencias, si bien en una primera impresión puede suscitar algunas dudas y puede ir unido a carencias puntuales, dota a la obra de un especial valor.

Se trata indudablemente de un enfoque que, al menos en parte, justifica que en su configuración este libro se aleje de otras obras generales, manuales o cursos al uso en España. Obviamente, su contenido poco tiene que ver con el de libros -más frecuentes en otras ramas del Derecho que en el DIPr- que pretenden ofrecer una obra de referencia en una materia, limitándose a poco más que reproducir con una cierta sistematización el contenido de normas, aderezadas ocasionalmente con ciertas referencias jurisprudenciales. Pero igualmente se halla muy alejado de otro tipo de obras generales abiertamente opuestas a las anteriores, como es el constituido por libros que supuestamente proporcionan la visión más actualizada, precisa y completa de un sector del ordenamiento, lo que se trata de probar y justificar, por ejemplo, mediante la inclusión (en una obra de referencia y carácter general) de listados pretendidamente exhaustivos o de gran valor de bibliografía preferentemente extranjera, que en la práctica resultan de escasa o nula utilidad, pues además en su mayor parte no han sido ni siquiera consideradas al redactar el texto de la obra en la que se incluyen. Ciertamente, en el actual marco tecnológico no hay tarea más sencilla que elaborar -0 copiar y pegar - una relación de trabajos relativos a una determinada materia, bien sean libros o artículos publicados en revistas, especialmente cuando en la lista no se discrimina entre trabajos que mantienen una postura y la contraria y, por supuesto, esos trabajos no han sido leídos y, muy probablemente, ni siquiera vistos.

4. Frente a ese modelo bien conocido en los últimos años, este Tratado proporciona un meditado estudio, en el que el autor toma partido, con una sólida argumentación propia, con respecto a las cuestiones controvertidas en los diversos sectores analizados, en ocasiones con un indudable carácter polémico y actual. Así lo refleja, a modo de ejemplo, su valoración del significado de la jurisprudencia constitucional en materia de filiación sobre la configuración del orden público o su postura crítica con algunas de las soluciones de la Ley de adopción internacional.

Por todo ello, no es de extrañar que paradójicamente este Tratado, tan clásico en algunos de sus planteamientos y tan alejado formalmente en buena parte de sus contenidos de la búsqueda de una aparente actualización, represente en muchos aspectos un soplo de aire fresco, que aporta una reflexión profunda e informada acerca de la evolución y configuración actual de los diversos sectores del DIPr.

Pedro A. DE Miguel Asensio Universidad Complutense 
Fontanellas Morell, J. M., La professio iuris sucesoria (Prólogo de Alegría Borrás), Madrid, Marcial Pons, 2010, 367 pp.

1. Tras años de exclusión del ámbito de aplicación material de los Reglamentos en materia civil y mercantil que han armonizado el Derecho internacional privado de los Estados miembros de la Unión Europea, las sucesiones conectadas con varios países se encuentran hoy por hoy en la agenda comunitaria, lo que dota de pertinencia y actualidad a toda obra sobre sucesiones internacionales que aborde esta problemática. Ya contamos con una Propuesta de Reglamento sobre sucesiones, que, a falta de asentar sus soluciones definitivamente, ha venido a colmar una necesidad que la propia Comisión Europea puso en su momento de relieve en diversos documentos preparatorios.

La Propuesta de Reglamento es un instrumento omnicomprensivo, esto es, aborda competencia judicial internacional, determinación de la ley aplicable y reconocimiento de decisiones extranjeras, amén de crear ex novo el llamado Certificado Sucesorio Europeo. Centrando nuestra atención en la determinación de la ley aplicable, la disparidad existente hoy día en este ámbito entre los distintos países europeos es notable. Entre otros aspectos, una de las diferencias más relevantes responde a la aceptación o rechazo de la autonomía de la voluntad. En otras palabras, mientras algunos países permiten al de cuius elegir la ley aplicable a su sucesión (de una forma más o menos limitada y generalmente de entre las alternativas proporcionadas por el legislador nacional), otros, como España, no han ofrecido tradicionalmente esta posibilidad.

2. De ahí que el autor de la obra objeto de este comentario comience la misma advirtiendo que puede causar extrañeza que un trabajo de investigación realizado en nuestro país se centre en una institución, la professio iuris suceso- ria, que nos resulta ajena. No obstante, la elección de ley en materia sucesoria viene discutiéndose desde antaño y, de seguir adelante la mencionada Propuesta de Reglamento con las soluciones que contempla en la actualidad, se extenderá por Europa, introduciéndose por primera vez en el Derecho internacional privado de sucesiones español.

Pero esto ocurrirá en el futuro, y lo que nos permite la obra de Josep M. Fontanellas en la Parte Primera es, por el contrario, adentrarnos en el origen y la evolución de la institución. Esta Primera Parte, que lleva por título «La professio iuris: raíces históricas y desarrollo en la ciencia moderna», consta de dos capítulos. El primero aborda «La professio iuris histórica», mientras el segundo estudia «La professio iuris en el Derecho internacional privado contemporáneo». En primer lugar, el estudio del origen y la evolución de esta institución jurídica, ampliamente documentado en la obra de referencia, resulta de especial interés. Para ello, el autor se ha trasladado hasta las culturas clásicas, la Antigua Grecia, Egipto, el Imperio Romano. A continuación, como decíamos, centra su atención en el Derecho internacional privado contemporáneo; en sus propias palabras, en «las diferentes manifestaciones de la professio iuris en el Derecho sucesorio internacional de nuestro tiempo», distinguiendo entre aportaciones de la doctrina científica, de diferentes legislaciones y de decisiones jurisprudenciales que se han pronunciado sobre la misma.

3. A continuación, la Segunda Parte de la obra, bajo el título «Naturaleza y valoración de la professio iuris sucesoria», analiza esta institución en profundidad a lo largo de otros dos capítulos: «Naturaleza y régimen jurídico de la professio iuris sucesoria» y «Examen crítico de la professio iuris sucesoria». Así, tras la aproxima- 
ción histórica a la figura de la professio iuris sucesoria, Josep M. Fontanellas nos indica que la Parte Segunda se consagra a analizar dos cuestiones: por un lado, su verdadera esencia jurídica y el régimen regulador de los múltiples aspectos en que puede escindirse su tratamiento jurídico; por otro lado, los distintos argumentos que, en el Derecho internacional privado del nuevo milenio militan a favor o en contra de la institución.

Finalmente, y a pesar de haber centrado su trabajo en el pasado y el presente de la institución, el autor no se resiste a realizar una breve valoración de futuro sobre la citada Propuesta de Reglamento. Se muestra así partidario de manera decidida de que se otorgue un papel a la elección de ley en materia sucesoria en dicho instrumento, concretamente a la posibilidad de que el causante - no sus herederos- pueda elegir la ley de su nacionalidad, tal y como se contempla hoy en la Propuesta, teniendo en cuenta además que el criterio de conexión objetivo por el que se ha decantado el legislador comunitario ha sido la residencia habitual. Por otro lado, también reclama un cierto espacio para la lex situs relativa a países extracomunitarios y la ley del régimen económico matrimonial.

4. En suma, la aprobación final del Reglamento europeo, que confiamos en que tenga lugar en un futuro próximo, conllevará no sólo la armonización conflictual de las sucesiones internacionales, sino también la introducción de la professio iuris sucesoria en nuestro Derecho internacional privado. Gracias a la interesante y oportuna obra de Josep M. Fontanellas, contamos con un análisis pormenorizado de dicha institución, donde encontrar desde su origen y evolución hasta los aspectos positivos y negativos que supone. Estaremos atentos a su introducción y desarrollo en la legislación y práctica española.

Carmen AzcÁRRaga Monzonís Universidad de Valencia

GARcía RocA, J., El margen de apreciación nacional en la interpretación del Convenio Europeo de Derechos Humanos: soberanía e integración, Civitas, Cuadernos Civitas, Thomson Reuters, 2010.

Se trata de un excelente análisis sobre el margen de apreciación nacional en la interpretación del Convenio Europeo de Derechos Humanos. El origen de esta noción es oscuro, como indica el autor, pero este estudio contribuye a avanzar en su sistematización, y en la reflexión en torno al mismo, de manera original e innovadora. La noción de margen de apreciación nacional no procede del Derecho internacional, no está en el convenio ni en los trabajos preparatorios y, seguramente, pudiera venir del Derecho francés (pp. 107-108). Consiste, indica el autor, en el «espacio de maniobra que las Instituciones de Estrasburgo están dispuestas a conceder a las autoridades internas en el cumplimiento de sus obligaciones derivadas del convenio europeo».
El objeto del libro es de calado, importancia y actualidad en una Europa en la que los derechos siguen siendo en gran medida una construcción estatal. Si bien el margen de apreciación ha sido objeto de reflexiones doctrinales previas, la que ahora se presenta es destacable por varias razones.

Se elabora la aproximación más desde el Derecho constitucional que desde el Derecho internacional, pero se manejan adecuadamente ambas perspectivas. Desde la perspectiva constitucional el «margen de apreciación» ha sido un asunto casi olvidado, aún siendo central en cualquier teoría europea de los derechos fundamentales, en la medida en que se quiera precisar el ámbito de auto- 
nomía del legislador y de los tribunales nacionales.

Desde la perspectiva internacional el autor ya había impulsado una investigación, junto a Fernández Sánchez, Pablo Antonio (Integración europea a través de derechos fundamentales: de un sistema binario a otro integrado, Madrid, Centro de Estudios Políticos y Constitucionales, 2009), que ahora profundiza en el tema de la investigación. El libro contribuye a comprender los criterios del tribunal, en un momento en que no es sencillo dado el elevado número de sentencias que se producen cada año.

En el primer capítulo (pp. 23-107) conecta los cambios de la noción de soberanía, en la tensión entre el poder supremo estatal y la integración supranacional para ver en qué casos es necesario restringir el control europeo en aras del margen nacional. Esta perspectiva parte de la consideración de un Derecho común, que no único, en Europa, en un escenario de pluralismo constitucional y rasgos originales (extraterritorialidad en la tutela de los derechos; doctrina de las obligaciones positivas de los Estados; integración entre ordenamientos y diálogo entre altos tribunales a que aboca el art. 10.2 de la Constitución).

Este Derecho común, que delimita un estándar mínimo europeo, tiene un efecto integrador y armonizador de los ordenamientos jurídicos estatales, pero no constituye un Derecho constitucional sino que se asienta en la soberanía del Estado, lo que explica algunas aplicaciones del margen de apreciación nacional. Por lo demás, la protección europea de los derechos humanos, como indica García Roca (p. 73), provoca dimensiones materialmente constitucionales, aunque la protección sea únicamente internacional, lo que es una limitación estructural que se traduce en el menguado efecto directo de las sentencias.

También se analizan los principios para el enjuiciamiento. Se parte de un innovador análisis del principio de proporcionalidad desde la perspectiva de las nociones de necesidad, margen de apreciación -que es un ingrediente del mismo-y subsidiariedad, sobre el que profundiza, al considerar que es inherente a la protección internacional y al margen de apreciación.

Desde estas bases se entra en un análisis exhaustivo del margen de apreciación. Se realiza un recorrido por las decisiones judiciales y por los elementos del margen de apreciación lo que contribuye a su sistematización, así como se clarifican los debates sobre la noción y su necesidad. A pesar de que, a juicio del autor, la construcción jurisprudencial es poco densa (p. 112), imprecisa (p. 118) e impredecible (p. 131), se avanza en la clarificación de las obligaciones de los Estados para su cumplimiento (véase pp. 156 y ss.), en la relación entre la doctrina del margen de apreciación y la doctrina del acto político (pp. 188 y ss.); concluye que en el sistema del convenio europeo no hay actos que por naturaleza no sean enjuiciables (p. 198). También se adentra el autor en el denominado principio de deferencia y en el juego del principio en relación con la naturaleza de cada Derecho.

Para García Roca la doctrina del margen de apreciación (p. 214) expresa el punto equidistante entre el Derecho internacional, del que emana el Convenio, que impone unas limitaciones al juicio europeo, y, en sentido contrario, el expansivo entorno que supone una garantía judicializada mediante el acceso directo de millares de individuos. Además, no constituye tanto un "privilegio procesal» o un derecho de los Estados demandados cuanto un método de autocontención judicial (p. 219).

El sentido del margen también está en la gran diversidad europea, en el pluralismo constitucional, a pesar de que hay un principio de integración funcional en torno a los derechos fundamentales. Para el autor el Convenio europeo 
(p. 241) no es un tratado más, sino que tiene un carácter supranacional antes que internacional; la Corte, indica, está en algún lugar en el camino entre un Tribunal internacional —definición que no explica todos sus rasgos-y un Tribunal constitucional — que no llega a ser-. En el capítulo $\mathrm{V}$ desciende al análisis de la aplicación judicial del concepto, seleccionando las sentencias más relevantes en relación con diversos derechos. El autor no se preocupa sólo de las nociones y conceptos, o de la misma jurisprudencia sino que, finalmente (pp. 313 y ss.) aborda también el margen de apreciación en el cumplimiento de las sentencias del Tribunal y en la ejecución de las medidas cautelares, así como de las (pp. 347 y ss.) incógnitas que derivan de la Carta de Derechos Fundamentales de la Unión Europea y de la futura adhesión de la UE al CEDH y sus consecuencias para la noción estudiada.

El autor finaliza haciendo unas reflexiones en las que cabe destacar que anuncia dificultades jurídicas y políticas en la adhesión de la UE al CEDH, pues la transición de un sistema binario a otro integrado en la protección supranacional apenas ha comenzado. De otro lado, concluye, el margen de apreciación nacional no constituye una verdadera doctrina (opinión ordenada que deriva directamente de la jurisprudencia a través de unos estándares abstractos, que sean previsibles), sino que es un criterio de decisión no reglado, flexible, pragmático y de aplicación irregular, de incierta sistematización doctrinal. Esta "herramienta», indica, junta a otras muchas reflexiones finales es necesaria en el actual estadio de la integración europea (p. 378), puede llegar a perdurar, y se conjuga con un positivo pluralismo que comporta el principio de subsidiariedad y el principio democrático. En definitiva, se trata de una contribución que ilumina muchas ideas sobre el papel del Convenio europeo desde la perspectiva de la construcción europea a través de los derechos y de una noción de gran relevancia en perspectiva iusinternacionalista.

Carlos R. FERnÁndez LIESA Universidad Carlos III

\section{Hinojosa Martínez, L. M., y Roldán Barbero, J. (coords.), Derecho interna- cional económico, Madrid, Marcial Pons, 2010.}

El Derecho Internacional Económico (DIE) se ha convertido, en estas últimas décadas y en consonancia con la creciente globalización de la economía, en una de las principales especialidades cultivadas por los iusinternacionalistas. La relevancia teórica y práctica del DIE y su cada vez mayor implantación en la docencia también han llevado a la publicación de manuales o tratados sobre la materia en diversos entornos, como el anglosajón, el francés, el italiano o el germano. Entre las obras pioneras, que han sido objeto de sucesivas ediciones, cumple referirse a JACKSON, J. H.; DAVEY, W. J., y Sykes, A. O., Legal Problems of International Economic Relations,
5. ${ }^{\mathrm{a}}$ ed., Saint Paul, American Casebook Series, 2008, con una primera edición que se remonta a 1977, y a CARREAU, D., y Juillard, P., Droit international économique, 3. ${ }^{a}$ ed., Paris, Dalloz, 2007, cuya primera edición, también con el profesor Flory, es de 1978. Más recientemente, se han publicado nuevos manuales sobre DIE, mayoritariamente en inglés, como LowENFELD, A. F., International Economic Law, 2. ${ }^{a}$ ed., New York, Oxford University Press, 2008, con una primera edición de 2002, y GuZMAN, A. T., y Sykes, A. O. (eds.), Research Handbook in International Economic Law, Cheltenham, Edward Elgar Publishing, 2007. 
A esta lista hay que sumar el libro colectivo objeto de la presente recensión, publicado dentro de la colección sobre «Derecho, economía y globalización» dirigida por los doctores Espósito y Bouzas, que ha sido coordinado por los doctores Hinojosa Martínez y Roldán Barbero y tiene como autores, junto a los indicados coordinadores, a otros ocho profesores vinculados a la fecunda escuela de iusinternacionalistas que se ha ido forjando, desde hace ya varios lustros, en la Universidad de Granada (por orden alfabético: Díez Peralta, Fajardo del Castillo, López Escudero, López-Jurado Romero de la Cruz, Marrero Rocha, Martín Rodríguez, Pérez Bernárdez y Segura Serrano).

Tal como destaca en el Prólogo el doctor Liñán Nogueras, que ha dirigido el Departamento de Derecho Internacional Público y Relaciones Internacionales de dicha Universidad durante dos décadas y ha estado vinculado a la formación de todos los autores del libro, éste «viene a llenar un vacío en la literatura jurídica en castellano». En efecto, aunque nuestra doctrina cuenta con destacados pioneros en el estudio del DIE (como, por ejemplo, el doctor Aguilar Navarro y su Ensayo de delimitación del Derecho internacional económico, Madrid, UCM, 1972, o el doctor Bermejo García y su monografía Comercio internacional y sistema monetario: aspectos jurídicos, Madrid, Civitas, 1990) $\mathrm{y}$ en estos últimos años se ha asistido a una multiplicación de las monografías, artículos y obras colectivas sobre diversos aspectos de esta materia, no hemos contado con un libro que, como éste, abordase, desde una perspectiva jurídica y de forma tan amplia y sistemática, los principales temas que integran el DIE. Cumple precisar que, a principios de este mismo año, se ha publicado, de forma casi simultánea a la obra que comento, el libro de FERnández Rozas, C., Sistema de Derecho económico internacional, Madrid, Civitas, 2010, que también viene a colmar dicha laguna.
El libro, coordinado por los doctores Hinojosa Martínez y Roldán Barbero, sitúa claramente el DIE como una «rama» del Derecho internacional público, sin perjuicio de sus peculiaridades y de las estrechas conexiones que mantiene con diversas vertientes del Derecho interno, el Derecho internacional privado y regulaciones «transnacionales». Los autores reconocen la complejidad de precisar los temas comprendidos bajo el DIE, dada la dificultad de delimitar "lo económico», que está presente, con mayor o menor intensidad, en buena parte de las materias reguladas por normas internacionales. Mientras que los manuales y tratados sobre el DIE más empleados actualmente (en particular, los de autores anglosajones) suelen concentrarse en tres grandes ámbitos (comercio internacional, sistema financiero y monetario internacional e inversiones extranjeras), el presente libro tiene el mérito de dedicar también un buen espacio a la cooperación para el desarrollo, el control de la actividad de las empresas multinacionales o la regulación internacional de los derechos de los trabajadores y su movilidad, aspectos que suelen ser soslayados en las visiones más «liberales» del DIE, que tienden a aislarlo de estos otros contenidos más sociales.

Habida cuenta de los múltiples y diversos temas abarcados por el libro, es muy adecuada su sistemática o estructura, dividida en cinco partes, dedicadas, respectivamente, a: 1) los fundamentos del DIE; 2) el comercio internacional; 3) el sistema financiero y monetario internacional; 4) la cooperación para el desarrollo, y 5) el Derecho internacional de la empresa y de los trabajadores. En función de dicha sistemática, el libro se va ocupando sucesivamente de las instancias internacionales más relevantes en cada ámbito, como la OMC, el FMI, la OCDE, el Banco Mundial, la ONU, el G-20, numerosas organizaciones y acuerdos de cooperación e integración económica regional, etcétera. 
Cada uno de los 18 capítulos del libro ha sido redactado por uno o dos autores, grandes conocedores de los temas a tratar, que suelen haber trabajado previamente en monografías u otras publicaciones. Se ha llevado a cabo una encomiable tarea de coordinación, que ha asegurado la unidad y coherencia del libro, donde abundan las remisiones o referencias cruzadas entre capítulos.

Se trata de una obra especialmente útil como libro de texto para la docencia del DIE, que hoy se imparte como asignatura optativa en la licenciatura o grado de Derecho y en otras enseñanzas de numerosas universidades. El libro conjuga muy bien su clara vocación didáctica con el rigor académico y se presenta en dos niveles de lectura: uno en letra normal y otro en letra reducida, donde el lector más interesado puede profundizar en los temas examinados y adentrarse en ilustrativos ejemplos, muchas veces extraídos de la abundante jurisprudencia citada (especialmente de la OMC y de tribunales arbitrales sobre inversiones extranjeras).

El libro se caracteriza por su claridad expositiva y, a la vez, por no conformarse con una presentación formalista $o$ descriptiva de los temas, pues procura resaltar lúcidamente los principales problemas que se plantean en cada ámbito tratado y enfocarlos desde un punto de vista crítico. Asimismo, se ofrece una visión muy actualizada de los temas, particularmente atenta, a lo largo de todo el libro, a las repercusiones de la grave crisis financiera y económica desatada en 2008 y a las propuestas formuladas para revisar (o apuntalar) la actual arquitectura del sistema económico internacional.

El libro también viene acompañado por unos útiles índices de jurisprudencia y materias (elaborados por los becarios de investigación Casado Guil y Marín
Aís) y un $\mathrm{CD}$ adjunto que contiene una nutrida relación de bibliografía adicional para cada capítulo y archivos con normativa, documentos o jurisprudencia, de los que pueden extraerse materiales de interés para la docencia.

Cabe precisar que la parte segunda del libro, dedicada al comercio internacional, es notoriamente la más extensa. Es lógico que así sea, pues se trata del sector jurídicamente más desarrollado del DIE, al que ya se dedican íntegramente algunos manuales y tratados. Comparto con los autores que, frente a la habitual visión del liberalismo económico como sinónimo de «desregulación», cumple reconocer que, por lo menos en el ámbito de los flujos internacionales de bienes y servicios, su progresiva liberalización ha requerido una creciente regulación internacional, que restringe el margen de maniobra de las políticas y normativas de los Estados, pues «los objetivos de extender y profundizar el libre comercio requieren no reglas laxas [...], sino un Derecho preciso, bien garantizado» (p. 62).

En suma, este libro nos ofrece una panorámica y a la vez rigurosa, crítica y actualizada "radiografía» del DIE, presentando los elementos esenciales de sus principales sectores y evidenciando la descompensación normativa e institucional que se da entre unos y otros, fruto de la variable voluntad política y de los intereses que impulsan sus respectivas regulaciones. Por consiguiente, considero que, además de ser un excelente libro para la docencia del DIE, también es una obra de sumo interés para todo aquel que quiera adentrarse en la compleja regulación jurídica de las relaciones económicas internacionales y sus actuales desafíos.

Xavier FERnÁndez Pons Universidad de Barcelona 
Maestre Casas, P.; Durán Ayago, A., y Velázquez Sánchez, M. ${ }^{a}$ M., Aplicación Práctica del Derecho internacional privado: casos y soluciones, 2. ${ }^{\mathrm{a}}$ ed. revisada y actualizada, Salamanca, Ratio legis, 2010, 289 pp.

Este reducto de libertad vital y profesional que constituye la cátedra universitaria ofrece pocos encargos tan gratificantes como el de recensionar una publicación que, como la presente, tiene su origen en un excelente trabajo de tres compañeras profesoras del Área de Derecho Internacional Privado de la Universidad de Salamanca, universitarias de primer nivel que rinden de forma renovada un homenaje académico a nuestro recordado y añorado compañero Inocencio García Velasco.

Aprehender, captar de forma tan sugerente y didáctica un ámbito tan complejo y heterogéneo como la dimensión y aplicación práctica de nuestra disciplina representa un reto doctrinal que la obra comentada logró ya en su primera edición, combinando una correcta selección de temas «motor» con la aportación de casos que permiten traer a colación los grandes temas de la asignatura.

Y esta segunda edición mejora la precedente, si cabe. No se limita a una actualización obligada de sistematización y de contenidos; aporta además un renovado elenco de casos prácticos, introduce ocho nuevos supuestos prácticos, y marcan unas pautas de solución a través del índice de cuestiones que sigue a cada caso y que permiten al operador jurídico y al estudiante captar la esencia del debate en presencia.

Llama la atención, y en positivo, la sistemática seguida, que responde a una orientación jerarquizadora de los problemas que circundan nuestra área de conocimiento y que demuestra un conocimiento de la práctica y del terreno doctrinal sobre el que se reflexiona, algo inhabitual ante la hipertrófica edición de obras jurídicas que saturan el mercado con visiones descriptivas huecas o vacías de contenido y de utilidad práctica.
Estamos ante un trabajo de referencia y de consulta obligada, en el bufete, en el aula y en el despacho universitario. Y es una obra que se adelanta al «espíritu Bolonia» (ensalzado por unos, vilipendiado o demonizado por otros), porque aporta una base de conocimiento útil, una identificación de problemas troncales y sus pautas de solución y además logra generar un poso obligado de información.

La propia estructura del libro revela la intención de superar un mero examen comparativo entre los bloques normativos en presencia y vigentes en la ordenación autónoma e internacional de nuestra disciplina, y es éste otro valor añadido de la publicación. Se comprueba así la elección de casos que conducen al recurso a la obligada técnica interdisciplinar en el estudio de un sector inherentemente internacional, y pueden apreciarse cuestiones vinculadas a objetos troncales de nuestra disciplina: ámbito de aplicación de los textos convencionales, problemas de aplicación, tratados sucesivos sobre una misma materia, técnicas de unificación/armonización internacional, junto a cuestiones vinculadas al arbitraje y selección de la ley aplicable.

La transversal óptica de análisis que nos ofrece esta suma de 45 casos supone otro factor positivo de valoración, porque tras la lectura global se alcanza un hilo conductor en las respuestas o soluciones que no se pierde tampoco pese a que se lean de forma aislada casos aislados.

Y este libro permite además demostrar el enorme potencial de análisis de nuestra disciplina internacional privatista, resultará sin duda atractiva también para miembros de disciplinas tradicionalmente afines a nuestro ámbito material y conflictual jurídico privado, como pueden ser los mercantilistas, procesalistas y civilistas. Lejos de absurdas peleas 
por celos temáticos la obra demuestra el valor añadido derivado de nuestra particular metodología de aproximación científica al mundo de la realidad privada internacional.

Y todo ello se presenta de forma especialmente atractiva o sugerente para el lector, ya que ofrece un ágil estilo de redacción, un excelente andamiaje a modo de estructura, y el propósito, alcanzado con brillantez, de proyectar todo su estudio (transversal o pluridisciplinar, desde una óptica material) sobre el prisma de análisis del Derecho internacional Privado. Sólo así se consigue dotar de contenido a campos de estudio y a genéricos conceptos que son hoy día «lugares comunes» a otras disciplinas jurídicas.
Los tres grandes bloques en que se estructura el libro: Derecho patrimonial internacional, Derecho de familia internacional y Derecho de sucesiones, subdivididos en las áreas de obligaciones contractuales, extracontractuales, derechos reales, sociedades y personas jurídicas, arbitraje comercial internacional, nombre de las personas físicas, matrimonio, parejas de hecho, filiación, secuestro internacional de menores, casos generales de familia (éstos, además, especialmente bien seleccionados) y Derecho de sucesiones logran aportar toda la creciente riqueza de matices jurídicos que nuestra disciplina aporta al ámbito de los estudios de Derecho.

Juan José Álvarez Rubio Universidad del País Vasco

Mariño MenéndeZ, F. M. (coord.), La aplicación del Derecho internacional de los derechos humanos en Derecho español, Universidad Carlos III de Madrid, Boletín Oficial del Estado, 2009.

La obra colectiva sobre La aplicación del Derecho internacional de los derechos humanos en Derecho español es fruto de diversos trabajos de especialistas en las materias abordadas, obra que es coordinada por el profesor Fernando M. Mariño Menéndez, director del Instituto Universitario Francisco de Victoria de la Universidad Carlos III de Madrid, catedrático de Derecho Internacional Público de dicha universidad.

En una valoración de conjunto esta obra refleja, por un lado, la sensibilidad del coordinador, gran especialista en Derecho internacional de los derechos humanos (DIDH) en relación con la recepción de normas (convencionales y consuetudinarias), principios y estándares internacionales sobre derechos humanos en Derecho español, no en vano el mismo es miembro del Comité contra la Tortura de las Naciones Unidas (ex Presidente de este Comité) y, por otro, la preocupación jurídica mostrada por cada uno de los autores en un intento de comprobar cómo el Derecho y la práctica española integran las normas, principios y estándares internacionales que obligan a España. Lo cierto es que el libro objeto de recensión, debería ser considerado como un excelente punto de partida para animar a los autores y a otros especialistas en derechos humanos a seguir profundizando en la aplicabilidad del DIDH en Derecho español.

Habida cuenta de la fecha de publicación (2009), la mayoría de los trabajos habrán sido concluidos en 2008, por lo que no pueden hacer referencia al Plan de Derechos Humanos, aprobado por el Consejo de Ministros (diciembre, 2008) y cuya Comisión de Seguimiento (Ministerio de la Presidencia), de la que soy miembro, fue instituida en junio de 2009. El Plan constituye un aporte sustancial a efectos de valorar la puesta en práctica de los compromisos internacionales asumidos por España, de hecho, algunas 
de las cuestiones abordadas en esta obra colectiva figuran entre las medidas contenidas en el Plan, por lo que el mismo puede aportar una multiplicidad de perspectivas de análisis, de políticas públicas y de técnicas de regulación que son necesarias, como avanza el Coordinador en el Prólogo de este libro.

En efecto, el profesor Mariño hace notar que la «complejidad de las cuestiones planteadas para la puesta en práctica de una eficaz protección de los derechos humanos exige el empleo de una multiplicidad de perspectivas de análisis, de políticas públicas y de técnicas de regulación y de solución de conflictos y litigios, que son transversales a la totalidad de cada uno de los ordenamientos en presencia» (p. 9), de ahí que también sostenga que "sólo grosso modo se podría clasificar esta obra en cuatro grandes apartados», aunque el libro en sí no está estructurado en apartados sino que en el índice del mismo están relacionados los distintos temas a abordar, habida cuenta de la complejidad de las cuestiones planteadas que, lógicamente, dificultan cualquier tipo de clasificación.

Sin pretender realizar una clasificación, me voy a permitir estructurar mis comentarios y propuestas del siguiente modo: 1) derecho a la vivienda; 2) grupos específicos de personas; 3 ) protección diplomática; 4) biomedicina; 5) España y los órganos internacionales de derechos humanos de Naciones Unidas; 6) Tribunal Europeo de Derechos Humanos; 7) justicia transicional y jurisdicción universal.

1. Ana Manero Salvador. («Los instrumentos universales sobre el derecho a la vivienda adecuada en España», pp. 81101), comienza su trabajo invocando el art. 10.2 de la Constitución Española (CE), y articula su análisis en la jurisprudencia internacional ya que el derecho a la vivienda no está incluido en nuestra Constitución entre los «derechos fundamentales», sino que está entre los principios rectores de la política económica y social. El análisis lo lleva a efecto en el ámbito de Naciones Unidas, por lo que se centra en el Pacto Internacional de Derechos Económicos, Sociales y Culturales. En este contexto hubiera sido pertinente recordar que España en el ejercicio de su soberanía decidió ratificar dicho tratado y que en el ejercicio de esa misma soberanía este Pacto fue incorporado a nuestro ordenamiento jurídico interno haciendo uso de la facultad que a tales efectos prevé el art. 96.1 CE. En todo caso una cuestión fundamental para el debate está relaciona con una afirmación del Relator Especial en su Informe, tras la visita a España por invitación del Gobierno (2006, párr. 86), y que reproduce con acierto la autora (pp. 99-100), lo que pone de manifiesto la deficiente aplicabilidad interna del derecho a la vivienda reconocido internacionalmente. Y ello sin perjuicio de lo pertinente que sería analizar la jurisprudencia de otros Comités de Naciones Unidas y del Comité Europeo de Derechos Sociales del Consejo de Europa para tener una visión más completa de la jurisprudencia internacional y la aplicabilidad o no de la misma en Derecho español.

2. Un segundo apartado se refiere a los grupos específicos de personas y en ellos:

a) Indígenas: Luis Rodríguez-Piñero Royo ( «La ratificación del Convenio núm. 169 de la OIT por España: más allá de la solidaridad», pp. 15-52), una de las cuestiones que aborda y que resulta del mayor interés a efectos de debate, sin que signifique que las demás no lo sean, está relacionada con la "obligatoriedad extraterritorial del Convenio» (pp. 3337). El autor parte de la afirmación de la «inexistencia de pueblos como los definidos en el art. 1 del Convenio» en España, pero considera que nada de lo dispuesto en el art. 2 del Convenio excluye, entre otras cosas, la obligatoriedad de los Estados «en toda acción exterior dirigida a estos pueblos», obligatoriedad que en el caso de España la considera reforzada por haber formado parte activa del gru- 
po de Estados amigos de la «Declaración de Naciones Unidas sobre los derechos de los pueblos indígenas» que finalmente, tras un largo proceso, fue aprobada por la Asamblea General (2007). Sobre la base de tales premisas afirma: "Nos encontramos así con un caso de obligatoriedad extraterritorial de un instrumento de derechos humanos», considerando por lo demás que «la obligatoriedad extraterritorial del Convenio para España, parece claro que éste tiene potencialmente alcances para las políticas públicas que componen la acción exterior del Estado en la medida en que éstas pueden tener un impacto en las obligaciones de respetar y hacer respetar los derechos recogidos en el Convenio», centrándose a continuación en el Convenio núm. 169 y en las Políticas Públicas (pp. 37-47), y prestando una especial atención a la «política de cooperación» (pp. 38-40).

b) Inmigrantes: Carmen Pérez González ( La cooperación entre España, Marruecos y Senegal en materia de prevención de la emigración de menores no acompañados, su protección y retorno al país de origen», pp. 137-158), comienza con el análisis de los Acuerdos concluidos por España con Marruecos y con Senegal para la prevención de la «emigración irregular» de menores de edad no acompañados. En todo caso, sería pertinente que en un debate posterior sobre esta materia se distinguiera con nitidez entre dos situaciones distintas, por un lado, «inmigración irregular» y, por otro, «trata de personas». Como también sería pertinente que se tuviera presente las «Observaciones finales» del Comité de los Derechos de los Niños (CRC/C/15/ Add. 185, de 2002) al examinar el segundo Informe presentado por España, toda vez que contiene recomendaciones (párr. 46) que resultan pertinentes a los efectos de comprobar la aplicabilidad o no de la mismas en Derecho español, fundamentalmente a la luz del Real Decreto 2339/2004 y de la jurisprudencia del Tribunal Constitucional (TC). Por su parte
J. Daniel Oliva Martínez («Protección Internacional de los Derechos Humanos y Derecho del Mar: el caso de los inmigrantes irregulares por vía marítima», pp. 159-185) se ocupa de las obligaciones de España relacionadas con los inmigrantes (así como otras personas: refugiados y polizones) que son interceptados, rescatados y auxiliados en vías marítimas, incluso en aguas internacionales, como también se ocupa del desembarco y repatriación de tales personas. Son muchas las cuestiones para el debate que suscita este trabajo, entre otras, ¿pueden ser calificados como inmigrantes, en situación irregular, aquellas personas interceptadas en aguas internacionales?

En el contexto de la inmigración, el último trabajo en esta obra está realizado por Ángel G. Chueca Sancho ( La aplicación de los tratados internacionales por el Tribunal Constitucional español en materia de extranjería», pp. 198-212), que una vez más nos ilustra magistralmente de cuestiones del máximo interés, en este caso, en relación con la «dignidad de la persona humana» y de determinados derechos (reunión, asociación, libertad y seguridad personal...) en relación con los extranjeros en general y, en especial, con aquellos que se encuentran en territorio español en situación de irregularidad, análisis que lleva a efecto sobre la base de la jurisprudencia del TC (con alusiones a la jurisprudencia del Tribunal Europeo de Derechos Humanos - TEDH-) y teniendo presente a tales efectos la Directiva de Retorno de Inmigrantes en situación irregular y la Ley Orgánica 4/2000. El autor pone de manifiesto que aun «con la valoración positiva que debe hacerse de esta jurisprudencia» (refiriéndose a la jurisprudencia del TC), la misma "mantiene intactas algunas incoherencias» (p. 210), por lo que plantea algunas preguntas del máximo interés a efectos de debate y que reproduzco: ¿Qué podemos hacer cuando una ley o cualquier otra norma de rango infraconstitucional contradiga frontalmente 
a un tratado internacional, que también forme parte de nuestro ordenamiento jurídico interno? ¿Esperaremos simplemente a que en el futuro una o varias sentencias del TC declaren a esas normas inconstitucionales, pero no por la citada contradicción? A ello añado a efectos de debate, ¿estaría justificada la no transposición de una Directiva de la UE, en materia de inmigración (o en cualquier otra materia), si la misma fuese incompatible con tratados internacionales de derechos vinculantes para España?

c) Víctimas del terrorismo: Félix Vacas Fernández («Derechos humanos y víctimas del terrorismo: del reconocimiento internacional a la protección y garantía de los derechos de las víctimas de terrorismo en España», pp. 103-135) hace referencia a la labor de las Naciones Unidas, del Consejo de Europa y, sobre todo, de la UE (pp. 108-125) a favor de los derechos de las víctimas del terrorismo, presentando una panorámica muy importante de la realidad en la materia. De lo que de este trabajo se deducen diversos temas para la reflexión, en los ámbitos mencionados, sobre todo en la UE tras la vigencia del Tratado de Lisboa, posterior a la publicación de esta obra. El autor concluye con una valoración muy positiva al sostener «el papel de liderazgo a nivel internacional de España en esta materia, no sólo en Europa sino también a nivel universal en el seno de las Naciones Unidas» (p. 135), no en vano con carácter previo cita (p. 126) lo afirmado por el Relator Especial sobre los Derechos Humanos y la Lucha contra el Terrorismo de Naciones Unidas en su Informe (A/ HRC/10/3/Add.2) tras la visita realizada a España (mayo, 2008). Pero dado que dicho Relator también realizó algunas recomendaciones (párrs. 53-65 del Informe), sería oportuno analizar si las mismas han sido tomadas o no en consideración por las autoridades españolas.

3. Un tercer bloque se refiere a la protección diplomática: M. ${ }^{\mathrm{a}}$ Amparo Alcoceba Gallego («Práctica española de protección diplomática y derechos humanos: titularidad del derecho y nacionalidad del beneficiario», pp. 213-236) distingue entre "protección diplomática», "asistencia consular» y "protección consular» y hace notar cómo en España la protección diplomática sigue siendo concebida en sentido clásico, esto es, como un derecho exclusivo del Estado. Hace constar asimismo que el elemento político constituye un importante condicionante para el ejercicio de la protección diplomática y para concebirla de forma distinta, por lo que concluye poniendo en cuestión que esta institución se pueda considerar como "posible mecanismo de protección internacional de los derechos humanos». Pero habida cuenta del importante desarrollo en materia de derechos humanos a nivel internacional, ¿la protección diplomática debe seguir siendo considerada como un derecho del Estado? ¿Sería posible realizar una interpretación similar a la que ha llevado a efecto la Corte Interamericana de Derechos Humanos y posteriormente la Corte Internacional de Justicia en relación con el art. 36 de la Convención de Viena sobre Relaciones Consulares?

4. La biomedicina encuentra su lugar en el trabajo de Jorge Zavala Salgado ( «La protección de los derechos humanos en la investigación biomédica: práctica de la aplicación de las normas internacionales en el ordenamiento jurídico español», pp. 53-79), tras hacer referencia a los instrumentos internacionales sobre la investigación biomédica, aborda una cuestión de la mayor relevancia referida a «la integración del Derecho internacional sanitario en el ordenamiento jurídico español» (pp. 64-68) a través de la Ley 41/02, reguladora de la "Autonomía del Paciente y de los Derechos y Obligaciones en materia de Información y documentación Clínica», haciendo asimismo referencia a otras leyes precedentes (LO 15/99 y Ley 35/1988) y realiza algunas alusiones a la jurisprudencia internacional y a la jurisprudencia de nuestro TC. 
Los casos mencionados por el autor son del mayor interés, como también lo son otros resueltos por el Comité de Derechos Humanos relacionados con cuestiones de salud. En todo caso, el lugar fundamental del análisis lo ocupa la Ley española de 2007 (pp. 68-79), "Ley de Investigación Biomédica», dado que la misma incorpora los principios del Convenio de Oviedo y su Protocolo adicional sobre biomedicina (Consejo de Europa) vinculantes para España. Si bien el autor se centra entre otras cuestiones, en los «embriones vivos» alude asimismo a una cuestión que resulta fundamental para el debate y está relacionada con el significado «ser humano» $\mathrm{y}$ "persona» toda vez que el Convenio de Oviedo reenvía al Derecho interno de los Estados partes para que los mismos precisen su significado.

5. Españay los órganos internacionales de derechos humanos constituye otro bloque: Carlos R. Fernández Liesa («Elaboración y aplicación del mecanismo de informes de derechos humanos en España», pp. 299-328) se centra en la preparación de los Informes por España para ser presentados ante los órganos de control internacionales (Comités) en relación con los tratados de derechos humanos que le resultan vinculantes, ilustrando con gran notoriedad sobre todos los problemas que encuentra en relación con los mismos. De las palabras del autor se deduce que sería pertinente una mayor toma de conciencia institucional para la preparación de los Informes a cuyos efectos realiza sugerencias. En este contexto considero oportuno señalar que sin olvidar que la obligación de informar es estatal, sin embargo, habida cuenta de que España es un Estado de estructura compleja, ¿en la preparación de Informes no deberían tener una participación notable las Comunidades Autónomas? ¿Y las instituciones nacionales de derechos humanos? Dado que las «Observaciones finales» expresan, en la mayoría de las ocasiones, los principales «motivos de preocupación», ¿se debe interpretar tales motivos de preocupación como un incumplimiento de las obligaciones internacionales asumidas? Las recomendaciones de los Comités en sus «Observaciones finales», ¿tienen finalidad de promoción y/o de protección? Si España no adopta las medidas oportunas para hacer efectivas las recomendaciones de los Comités, ¿podría interpretarse que está actuando de forma incompatible con el tratado pertinente? Por su parte, Pilar Trinidad Núez ( «La aplicación judicial de España de las decisiones de los órganos de base convencional de supervisión de derechos humanos creados en el seno de las Naciones Unidas», pp. 329-349), aborda diversas cuestiones, una de ellas, la que desde hace años está resultando un «látigo» para España, los dictámenes del Comités de Derechos Humanos declarando violación del art. 14.5 del Pacto Internacional de Derechos Civiles y Políticos (problema sobre la doble instancia judicial en materia penal). En relación con esta cuestión cabe plantearse, ¿la LO 19/2003 que modifica la LO 6/1985 del Poder Judicial, es adecuada a lo exigido en el art. 14.5 del Pacto?

6. Al Tribunal Europeo de Derechos Humanos se dedica al trabajo de Alicia Cebada Romero ( El futuro del Tribunal Europeo de Derechos Humanos: ¿hacia el Protocolo 15?», pp. 237-274) se centra en un tema del mayor interés relacionado con el Tribunal Europeo de Derechos Humanos (TEDH). La autora alude a la situación bien conocida del colapso en la que se encuentra el mismo y a la adopción del Protocolo de Enmienda núm. 14 para intentar paliarlo, en la medida de lo posible. También señala que «trascendencia constitucional» [exigida en la nueva LO 6/2007, art. 50.1.b) del TC español] $\mathrm{y}$ "perjuicio importante» (al que hace referencia el Protocolo núm. 14, entrado en vigor en junio de 2010) no es lo mismo. En este contexto cabe plantear, ¿tales conceptos difieren en cuanto a sus efectos? Por otro lado es cierto que el Convenio Europeo de Derechos Humanos no tiene la misma posición en el ordenamiento ju- 
rídico interno de todos los Estados parte, pero ello ¿constituye fundamento para cuestionar la obligatoriedad —para el Estado demandado, responsable internacional- de lo resuelto por el TEDH mediante sentencia motivada? ¿Introduce alguna novedad significativa el Protocolo núm. 14 sobre la obligatoriedad de las sentencias del Tribunal? ¿Se merece el TEDH un nuevo Protocolo de Enmienda núm. 15 o por el contrario sería permitente ir de forma más pausada y poner en práctica la aplicación del Protocolo núm. 14, sobre todo, ante la perspectiva de la adhesión de la UE al Convenio?

7. Finalmene, un último apartado se refiere a la Justicia transicional y jurisdicción universal: Pablo Zapatero Miguel («Justicia transicional y jurisdicción universal: el caso de Guatemala-España», pp. 275-297), hace referencia, entre otras cuestiones, a la complejidad del iter procesal del caso analizado, así como a la acción judicial lateral, aludiendo por lo demás a las buenas y malas prácticas judiciales. El autor por lo demás sostiene (refiriéndose a los asesinatos de ciudadanos españoles y guatemaltecos en dependencias oficiales del Estado español y al silencio a balazos de ciudadanos -indígenas-guatemaltecos en dependencias diplomáticas españolas) que «los ecos vuelven a escucharse en España en el marco de un proceso de jurisdicción universal», a lo que añade: «Por ello, el actual gobierno español debe impulsar enérgicamente el proceso de justicia transicional en Guatemala» (p. 295). Habida cuenta de la modificación del art. 23 de la Ley Orgánica del Poder Judicial, ¿un caso, como el guatemalteco, al que hace referencia el autor, sería posible que fuera conocido en la actualidad por los tribunales españoles en un proceso de jurisdicción universal? ¿España ha asumido para sí misma el proceso de justicia transicional?

Ana M. SAlado Osuna Universidad de Sevilla

\section{Morán Blanco, S, y González Martín, A., Asimetría, guerras e información, Madrid, Dilex, 2009.}

La historia reciente de la guerra confirma, con seguridad, una tendencia que, desde siempre pero ahora con más fuer$\mathrm{za}$, descubre posibilidades de éxito crecientes a los más débiles. Incluso los muy débiles «tienen opciones» y por eso deciden enfrentarse a los más poderosos. Y, en ocasiones, David se impone a Goliat. En este contexto, el sistema internacional, en pleno proceso de globalización, descubre nuevos protagonistas y nuevos escenarios que reclaman, con creciente intensidad, la convergencia coherente de acciones y discursos en un contexto de guerra. Las lógicas de la guerra y de la política, siendo distintas, actúan cada vez más en paralelo. La tecnología ha globalizado los flujos de información permitiendo a los medios de comunicación social convertir el mundo en lo que se denomina «un gran patio de butacas».
Todo es visible desde cualquier rincón del Planeta. La política y la guerra se hacen en medio de la gente y la conquista de sus corazones y sus mentes es, en gran parte, su objetivo porque de ello depende el triunfo. Todas estas cuestiones son analizadas, con detalle, en la obra que ahora comentamos y en las que sus autores, con rigor y acierto, van situando los énfasis en aquellas cuestiones de mayor interés.

La nueva situación está provocando, con seguridad, un desplazamiento del centro de gravedad del poder, que está dejando de ser dominio de lo real y tangible para ser cada día más dominio de lo virtual. Los propios autores así lo confirman: «El componente inmaterial, de esta manera, desde el centro, ordena todo a su alrededor en una sintonía que estructura 
tiempo, espacio, fuerza y mensaje para influir sobre las decisiones del público capturando sus percepciones y expectativas. En este panorama, la batalla de las ideas, de los relatos, de las narrativas es la batalla decisiva, que necesita movilizar discursos y provocar emociones colocando delante de los espectadores palabras e imágenes seleccionadas de la realidad. El dominio de la información es una posición fundamental que debe conquistarse, ocuparse y defenderse a toda costa, se ha convertido en la clave táctica del problema». Por esto, "Asimetría, guerra e información», título de este trabajo, «son líneas de operaciones que nos descubren cómo el equilibrio de fuerzas depende cada vez más del equilibrio de mensajes y significados».

Los autores de la obra analizan, con detalle, algunos de los conflictos armados más mediáticos del mundo actual desde ópticas diferentes, derivadas de su distinta formación pero, en los dos casos, con visiones científicas muy correctas y complementarias. La doctora Sagrario Morán desde la perspectiva de las relaciones internacionales y el teniente coronel Andrés González desde la óptica de la estrategia, la historia y la filosofía. Como decimos, ambos aportan puntos de vista que, de manera complementaria, han contribuido a enriquecer un trabajo llamado a convertirse en una referencia para todos aquellos que estén interesados en el estudio de los Conflictos Asimétricos. Como señala de manera muy acertada en el prólogo, el general de brigada y director del Instituto Español de Estudios Estratégicos del Ministerio de Defensa, Miguel Ángel Ballesteros: «Cualquier estrategia que pretenda hacer frente con éxito a aquellos que han encontrado en el conflicto asimétrico una forma de alcanzar objetivos políticos, superando la debilidad de sus recursos y capacidades, lleva al extremo la muy conocida idea de Clausewitz de que la Guerra es la continuación de la política por otros medios. Una guerra al alcance de los débiles, que parece que será la fórmula empleada por éstos en el futuro». Ahí están, como no, los ejemplos de Irak o Afganistán.

Los autores, con acierto, hacen un completo análisis conceptual sobre el empleo de las estrategias asimétricas a lo largo de la historia de la guerra. En concreto, Andrés González elabora un capítulo, titulado "La Pedagogía de la Paz y el Estudio de la Guerra», en el que se centra en el estudio del componente filosófico de la guerra y sus características principales, como son la incertidumbre o la diferente visión que de ella tienen los actores implicados y, de esta forma, realiza un excelente análisis de muchos de los aspectos que resultan de interés para una ulterior delimitación jurídica. Mientras, la profesora Sagrario Morán lleva a cabo, de manera muy minuciosa, un examen de la evolución histórica presentando las diferentes generaciones de la guerra. Para la doctora Sagrario Morán hoy estamos en la cuarta generación de la guerra, lo que en Estados Unidos se llama Fourth Generation Warfare "4GW». En particular, cabe resaltar que en el capítulo II, dedicado a esta nueva generación de la guerra, se hace un profundo e interesante análisis de los actores, medios y principales características de las denominadas Guerras de Cuarta Generación. Como se desprende de la lectura del trabajo, una guerra con sus propias claves, que sucede entre la población y la población es la principal baja, en manifiesta violación al DIH, y donde, como decía un general norteamericano, "lo importante es conquistar los corazones y las mentes». Pero, asimismo, corresponde indicar que, en el capítulo III, la autora, con buen criterio, examina los límites legales que los Estados no deben sobrepasar en el uso de la fuerza en este tipo de conflictos pero que, sin embargo, rebasan en la práctica internacional. Especialmente interesante resultan los ejemplos de los últimos conflictos armados donde las principales potencias occidentales no han respetado las reglas 
del juego del Derecho internacional. Con ello, la doctora Morán no sólo pone de manifiesto su formación en las relaciones internacionales sino cómo penetra, con facilidad, en el campo del ordenamiento jurídico internacional.

El lector también encontrará un amplio e interesante capítulo dedicado al papel que juegan los medios de comunicación en los conflictos armados, con lo que se completa la visión, ya que se pone el acento en la relación que existe entre conflicto y medios de comunicación. Hoy ya nadie duda de que este papel es clave en la resolución de las guerras. Pero, como se sabe, no siempre ha sido así. Tal y como se explica en la obra que ahora comentamos, la importancia de los reporteros de guerra no ha dejado de aumentar desde la Guerra de Crimea (1854-1856), cubierta por el mítico William Howard Russell, corresponsal de The Times en Londres, considerado pionero de los actuales corresponsales de guerra. En los conflictos asimétricos los profesionales de la información se convierten en actores clave, porque el bando débil tratará de utilizar la presión de la opinión pública sobre sus gobiernos para doblegar su voluntad. Esto es algo que se vio en la Guerra de Vietnam, las fotos de los caídos o las imágenes de los ataúdes con soldados estadounidenses, retransmitidas por la televisión, entonces en blanco y negro, afectaron especialmente la percepción del público respecto a la guerra de Vietnam. Las diferentes formas de relación entre reporteros y militares, casi siempre pésimas a lo largo de la historia, y la importancia del trabajo de los reporteros para permitir que la opinión pública esté bien informada, en ocasiones son decisivas en el resultado final de la guerra. En definitiva, el lector encontrará un trabajo bien hecho y, sobre todo, una obra que le será muy útil para conocer, desde perspectivas diferentes, fenómenos de gran actualidad en la escena internacional. La elección del tema por los autores no puede ser mejor, a lo que se añade la seriedad y el rigor científico con los que se analiza.

Cástor Miguel DíAz BARRAdo

Universidad Rey Juan Carlos

MuÑoz Fernández, A., La protección del adulto en el Derecho internacional privado, Cizur Menor (Navarra), The Global Law Collection, Thomson Aranzadi, 2009, 308 pp.

Si el siglo xx fue el siglo de los niños, el siglo XXI será el siglo de los mayores. La curiosidad científica, auxiliada por el rigor metodológico, llevó al doctor $\mathrm{Mu}$ ñoz Fernández a elaborar su tesis doctoral sobre La protección del adulto en el Derecho internacional privado, dirigida por el profesor Iriarte de Ángel y defendida en la Universidad de Navarra en mayo de 2007, ante un tribunal del que honrosamente formé parte. Éste es el antecedente inmediato de la monografía que presentamos. Por ello, puedo señalar, en primer lugar, que el autor ha recogido muchas de las observaciones que en su día se le hicieron, ha profundizado en los planteamientos y, sobre todo, ha sabido mantener e incluso vigorizar sus propuestas más originales, que cobran especial relevancia con la entrada en vigor el 1 de enero de 2009 del Convenio de La Haya sobre Protección internacional de adultos de 13 de enero de 2000, ratificado por Alemania, Francia, Reino Unido de Gran Bretaña e Irlanda del Norte y Suiza.

Subrayo, de entrada, curiosidad científica y rigor metodológico, mérito de la obra y cualidad del autor, a la que habría que sumar hondura en la reflexión, que se ponen de manifiesto en la cuidada In- 
troducción. Una Introducción, como tal, que dibuja el itinerario del estudio, acota su ámbito y señala las preocupaciones del autor. A las que no sustrae su sensibilidad hacia los problemas analizados $\mathrm{y}$, a veces le lleva a derivar al adulto en mayor, con relativa imprecisión terminológica, que no merma ni la seriedad del análisis ni el valor de sus resultados.

De las dificultades terminológicas es consciente el autor. Así, en la primera parte, dedicada al «Nuevo marco jurídico y sociológico de la protección internacional del adulto», el primero de sus dos capítulos está, precisamente, dedicado tanto a delimitar como a conceptuar la misma noción de adulto, al tiempo que penetra en el tenor y significado de las medidas para su protección en el marco del Convenio de La Haya sobre Protección Internacional de Adultos de 13 de enero de 2000. Esta consideración de las medidas de protección, en el marco del Convenio, sirve al autor para un buen ejercicio de comparatismo, que no mera enunciación, descripción y yuxtaposición de normas de diferentes países. El doctor Muñoz Fernández revela algunas de las más significativas tendencias y elementos de Derecho comparado en cuanto concierne al contenido de las medidas de protección. Cuando el lector ha obtenido, gracias a la cuidada redacción del libro, una información bien construida acerca de los diferentes modelos de protección, en un crescendo de interés, el autor nos coloca frontalmente ante el envejecimiento de la población y el incremento de las situaciones (durables o transitorias) con elementos de extranjería internacionales; es lo que el autor denomina el sustrato sociológico, al que dedica el capítulo segundo, militando en pro del Convenio de La Haya sobre Protección Internacional de Adultos y por la necesidad de una regulación específica de la protección internacional del adulto (¿o del mayor?), desde el conocimiento de la realidad regulada.

La segunda parte del libro que comentamos se centra en las cuestiones más técnicas y especializadas de «La protección del adulto en el Derecho internacional privado. Análisis comparativo con la protección del niño». En el capítulo III se analiza la protección de incapaces, sin distingo de edad, con un corrector planteamiento histórico y, de nuevo, con abundantes elementos de Derecho comparado. Las dificultades terminológicas señaladas se convierten ahora en un escollo metódico, que el autor reconoce y salva pues la protección de incapaces precede, en muchas ocasiones, a la protección del niño o del adulto, para proporcionar la tutela jurídica en atención a la capitidisminución no condicionada por la edad. Esta «disfunción» se pone de manifiesto tanto en este capítulo como en el capítulo V.

El núcleo del libro lo encontramos en capítulo IV, «Aspectos particulares de la protección del adulto en el Derecho internacional privado: análisis comparativo con la protección del niño en el marco de los nuevos Convenios de La Haya». El autor realiza un cuidado y meticuloso parangón de los Convenios, con aclaraciones esmeradas y explicaciones exactas y, sobre todo, de sumo provecho para los operadores jurídicos. En este capítulo late la larga evolución jurídica que conduce desde la familia como única instancia, pasando por el modelo de tutela de autoridad de los años ochenta del siglo pasado, hasta el alumbramiento de un nuevo modelo de "autotutela», fundado en posibilitar y permitir a la persona planificar su futuro, mientras se conservan las facultades mentales. Por eso, la voluntad del adulto es uno de los aspectos más importantes y novedosos del Convenio, que el doctor Muñoz Fernández estudia con gran seriedad, tanto en sus aspectos sustantivos como en la perspectiva de las reglas de reconocimiento y ejecución del Convenio.

El quinto y último capítulo está dedicado a la «Protección del adulto en el Derecho internacional privado español». Las consecuencias del cambio de modelo 
de protección, sirven al autor para realizar atinadas consideraciones desde la perspectiva de la calificación de los supuestos de hechos, cernida por los peligros de unas situaciones que por estar pegadas a la vida, en su más literal sentido, no siempre se acomodan a instituciones que tienen mucho de constructos. Hechas estas observaciones, el doctor Muñoz Fernández aborda los problemas de la competencia judicial internacional, la cooperación de autoridades y la ley aplicable. Especial atención dedica a las figuras de autotutela o negocios jurídicos de autoprotección. El autor nos plantea con gran agudeza los problemas que suscita el Convenio al imponer su reconocimiento incluso cuando sean desconocidos como tales en el Derecho interno (lo que no es el caso de España). Al hilo de estos argumentos, realiza con seriedad reflexiva, mesura de juicio y madurez de planteamientos propuestas útiles y razonadas para la actualización del régimen jurídico de la protección del adulto en el Derecho internacional privado. Estamos pues ante una monografía de referencia.

Pilar Blanco-Morales Limones Universidad de Extremadura

\section{Pascual Vives, F. J., El Derecho de los Tratados en la jurisprudencia comunita- ria, Valencia, Universidad de Alicante, Tirant lo Blanch, Colección Mono- grafías núm. 614, 2009.}

Esta monografía presenta una elaborada tesis doctoral con un tema de fondo complejo por su transversalidad. En estos tiempos de currículos académicos superficiales y fáciles es de agradecer un tema de tesis sobre cuestiones centrales $\mathrm{y}$ abstractas que se proyectan en innumerables instituciones y situaciones jurídicas de la práctica normativa y judicial y permiten a su autor una formación integral sólida para despegar en su carrera académica.

El doctor Pascual Vives, bajo la dirección esmerada y perfeccionista del doctor Carlos Jiménez Piernas, ha llevado a cabo un análisis minucioso y sistemático de la jurisprudencia del Tribunal de Justicia de la Unión Europea en todos los ámbitos de la aplicación del Derecho de los Tratados a la acción normativa internacional de la Unión. Se hace un examen de contraste de la aplicación de las reglas de ese sector central del Derecho internacional en materias tales como la formación de la voluntad y la manifestación del consentimiento, las reservas, las excepciones al principio de la relatividad de los Tratados y la responsabilidad de su cumplimiento, que son analizadas desde la óptica de las consecuencias de un sistema de integración en la práctica convencional a la luz del Derecho de los Tratados. En definitiva, cómo se incorporan y se aplican los tratados internacionales en la Unión y, por tanto, qué aportaciones ha hecho la práctica jurídica de las instituciones de la Unión y la de los órganos internos de sus Estados miembros.

Estas cuestiones principales y otras son analizadas a la luz de la interacción e interdependencia entre el ordenamiento internacional, el sistema de la integración y el Derecho interno. Su autor sistematiza su análisis en torno a las tres grandes opciones del Tribunal de Justicia. Entiende que la «opción asimiladora» se produce en aquellas soluciones jurisprudenciales en las que prescinden de instituciones particulares propias del subsistema de integración y hace prevalecer lo general sobre lo particular, tal como sucede en materia de responsabilidad internacional, reservas, creación de obligaciones para terceros, nulidad e interpretación de los acuerdos internacionales. 
El manejo del principio de estabilidad de las relaciones convencionales por el Tribunal de Justicia de la Unión ante posibles vicios del consentimiento y situaciones de nulidad abona el predicamento de lo general sobre lo particular recurriendo a la necesaria subsanación del acto interno sin que ello ponga en peligro principios constitucionales de la propia Unión como el del equilibrio institucional. El autor estima que son idóneas las herramientas asimiladoras del Tribunal de la Unión para acomodar el Derecho de los Tratados a las exigencias institucionales.

Por el contrario, en otras ocasiones el Tribunal se inclina por utilizar instrumentos específicos del subsistema regional y es lo que el doctor Pascual Vives denomina la «opción privativa». Su utilización, como precisa el autor, es respetuosa con los predicados del Derecho internacional $\mathrm{y}$, a pesar de ser opciones propias, siguen representando, como demuestra el autor, un compromiso entre lo general y lo particular en una sociedad internacional heterogénea.

Se analiza, entre otros ejemplos y con sumo detalle doctrinal y jurisprudencial, como es constante a lo largo de toda la obra, la doctrina de la convalidación del mandato negociador, su relación con el principio de competencias de atribución, el de la buena fe y la estabilidad de los compromisos adoptados. Resultan particularmente interesantes sus consideraciones acerca de la objetivación del principio de la buena fe durante la celebración de los acuerdos internacionales hasta el punto de constituir una norma consuetudinaria regional o el impacto de la cláusula del elemento esencial en las relaciones con el grupo de Estados de África, Caribe y Pacífico y en contextos al margen de esos acuerdos con los ACP. El autor de la obra afirma que esta institución comunitaria podría calificarse como norma consuetudinaria y trasladarse hacia otros sistemas de integración.
Frente a esas dos opciones con un pluralismo jurídico abierto pero ortodoxo, el autor agrupa bajo una tercera opción, la «opción fragmentadora», en la que la soluciones jurisprudenciales no se adecuan al ordenamiento internacional y no se logra la necesaria coordinación entre el sistema de base y el sistema derivado. La dialéctica y la cohabitación entre lo general y lo particular desaparece y ocupa el terreno la opción peculiar regional. Se analizan sentencias en las que el Tribunal de Justicia de la Unión se aparta intencionadamente de opciones iusinternacionalistas idóneas para resolver el litigio. Un ámbito particularmente importante para el autor es el relativo a tratados sucesivos sobre una misma materia en el que el Tribunal de Justicia se aparta de las reglas tradicionales del Derecho de los tratados para decantarse por las de la terminación de los tratados, si bien estima que en ese asunto hubo consideraciones extrajudiciales o políticas para favorecer a Francia frente a otros socios comunitarios.

También toma como referente fragmentador la controvertida jurisprudencia del Tribunal de Justicia de la Unión respecto a la aplicación directa de los acuerdos de la Organización Mundial de Comercio. Es bien sabido que el Tribunal de Justicia se aparta, por puras razones políticas, de su doctrina sobre el efecto directo de los acuerdos internacionales que vinculan a la Unión cuando se trata de los acuerdos de la OMC al amparo del principio de reciprocidad para salvaguardar intereses comerciales de los operadores europeos en Estados Unidos, donde tales acuerdos no gozan de eficacia directa. Ahora bien, el autor tiene en cuenta que esa opción fragmentadora no afecta a los derechos que los particulares puedan deducir a la luz del ordenamiento interno, en especial en el terreno del Acuerdo sobre los Aspectos de los Derechos de la Propiedad Intelectual relacionados con el Comercio (ADPIC). En efecto, son muy numerosas las sentencias de 
tribunales nacionales reconociendo el efecto directo de Acuerdo ADPIC.

En la monografía resalta el tratamiento pormenorizado de materiales de primera mano tales como la jurisprudencia internacional clásica de la Corte Permanente, de la Corte Internacional de Justicia y jurisprudencia arbitral internacional, así como de la regional europea del Tribunal de Justicia y de la Corte Europea de Derecho Humanos. Igualmente la fundamentación basada en los trabajos de la Comisión de Derecho Internacional y en una exhaustiva interpretación doctrinal avalan la lectura reposada y concienzuda de su autor.

Esta obra se suma así a una preocupación sobre las relaciones de interdependencia entre los distintos sistemas jurídicos que confluyen hoy en día para regular una misma situación jurídica en una sociedad internacional fuertemente heterogénea en la que conviven sistemas jurídicos regionales con el general. Este fenómeno del pluralismo normativo no es nuevo ni único ni se circunscribe a los fenómenos de integración. Como el propio autor reconoce las consecuencias del pluralismo jurídico son bien conocidas en materia de derechos humanos.

En todo caso, desde la perspectiva central del objeto de la monografía comentada, en palabras del autor, la aplicación del Derecho de los Tratados en el seno de la Unión ha sido positiva y beneficiosa al constatarse la existencia de mecanismos de interacción coherentes entre ambos ordenamientos que han llevado al desarrollo progresivo del Derecho de los tratados aplicables a las organizaciones internacionales.

Estamos ante una práctica constante y uniforme en el seno europeo, si bien no cabe extrapolar esas soluciones particulares a otros contextos sino con sumo cuidado. En conclusión, rigor, prudencia y excelente argumentación adornan las tesis del autor.

Araceli MANGas Martín Universidad de Salamanca

\section{Quiñones Escámez, A.; Rodríguez Benot, A.; ZeKri, H., y OuHidA, J., Kafala y adopción en las relaciones hispano-marroquies, Madrid, FIIAPP, 2009, pp. 157-197.}

He aquí una interesante obra que reúne tres estudios sobre la kafala y que permite al lector contemplar un escenario jurídico sugerente en torno a esta institución legal. Rompe el hielo el estudio de $\mathrm{H}$. Zekri y J. Ouhida, con el título «La kafala en el Derecho marroquí» (pp. 11-125), del que pueden ponerse de relieve cuatro aspectos distintos. En primer lugar, llama la atención la traducción que las autoras hacen del vocablo "kafala», definido por ellas como «acogimiento familiar permanente». Ello refleja, sin duda, que la traducción de conceptos de un idioma a otro comporta, de manera imperceptible pero también inevitable, un intento de traducir instituciones jurídicas desde un ordenamiento jurídico a otro. Este primer aspecto debe ser conectado con el hecho de que las instituciones jurídicas desconocidas en un ordenamiento jurídico pueden presentar distintos grados de desconocimiento: unas resultan «más desconocidas que otras». En definitiva, es discutible que con conceptos e instituciones jurídicas del Derecho español se puedan definir instituciones jurídicas desconocidas procedentes de un Derecho extranjero. Decía M. Heidegger que su filosofía sólo podía formularse adecuadamente en lengua alemana y no le faltaba razón. En la arena jurídica sucede algo parecido, de modo que la definición de la "kafala» sólo se puede realizar correctamente mediante los instrumentos legales propios del ordenamiento jurídico en el 
que se regula y se contempla la kafala y no mediante las herramientas conceptuales del Derecho español. Se puede hacer, pero será, por fuerza, una aproximación conceptual inexacta. Hay que caminar con sumo cuidado. Un segundo aspecto llama la atención de forma poderosa: el estudio se centra en el Derecho marroquí. Y es sabido que la kafala existe en otros muchos países cuyos ordenamientos jurídicos presentan una raíz coránica y que, por ello, la regulación de la kafala e incluso su función legal es, naturalmente, distinta de país a país. No existe «una kafala»: existe la kafala del Derecho marroquí, la kafala del Derecho argelino, la kafala del Derecho egipcio... En tercer lugar, también resulta curioso el arranque del estudio, focalizado de forma muy directa en tratar de desmentir la versión más difundida en Europa del origen de la kafala y que ha sido bien expuesta, entre otros, por F. Calvo Babío (CALvo Bавío, F., Reconocimiento en España de las adopciones simples realizadas en el extranjero, Madrid, Univ. RJC, Dykinson, 2003, pp. 13-15). Sin entrar aquí en el debate, las autoras recurren a versiones alternativas de la historia original construidas sobre los distintos comentarios del Corán elaborados por diferentes comentaristas del mismo. En fin, lo que es claro al jurista es que la existencia de la kafala en Derecho musulmán se vincula directamente con la expresa prohibición de la adopción en la cultura jurídica islámica (versículos 4 y 5 de la Sura XXXIII). Por último, cabe subrayar que el estudio reseñado, centrado en la kafala (versión marroquí), resulta interesante y rico en matices, pues acerca al lector al conocimiento de una institución jurídica desconocida en Derecho español y cubre aspectos de fondo y de procedimiento desde la preocupación que genera la práctica relativa al traslado de niños «kafalados» fuera de Marruecos, en especial cuando no es posible realizar un seguimiento del grado de cumplimiento por parte del acogedor, de sus obligaciones (p. 33). Si bien cabe señalar que en algún momento se produce cierta confusión entre la regulación anterior y la actual relativa a la kafala marroquí (véase p. 23, que hace referencia a que el huérfano para ser considerado "abandonado", es necesario que no disponga de medios legítimos para subsistir). La actual regulación sólo se refiere a que sea huérfano, si bien quizás pudiera entenderse que debería estar en situación de «abandono». El trabajo aparece acompañado por un muy útil anexo con textos legales, judiciales y administrativos que siempre ayuda al profano a navegar con correctos instrumentos de orientación jurídica por las procelosas aguas del Derecho islámico.

El segundo estudio corresponde a A. Rodríguez-Benot (Rodríguez-BEnot, A., «Eficacia de la kafala ante el ordenamiento español», pp. 127-155). Resulta altamente recomendable la exposición que el autor realiza del iter jurídico de la kafala ya constituida en país extranjero cuando el makful trata de ser introducido en España. Ello exige un doble enfoque de Derecho administrativo (Derecho de extranjería), por un lado, y de Derecho internacional privado (Ley aplicable a cuestiones de Derecho privado) por otro lado. Doble enfoque que el autor aborda con solvencia y que proporciona un sesgo práctico de valor muy notable (pp. 132139). Ya en la perspectiva sustantiva, el autor expone con gran solvencia los aspectos jurídicos más problemáticos que se plantean a partir del momento en el que la Ley 54/2007 impide toda equiparación automática entre kafala y «adopción de tipo español». Así, en primer término, queda expuesto el mecanismo que recoge el art. 34 de la Ley 54/2007 de adopción internacional para facilitar la constitución de una adopción española a partir de una kafala válidamente constituida en el extranjero. En segundo término, A. Rodríguez-Benot indica, con su habitual perspicacia, que este art. 34 LAI ni obliga a la kafala a transformarse en adopción de tipo español ni equipara sin más la kafala a dicho acogimiento como condición 
para que la misma surta efectos legales en España. Lo que este art. 34 LAI señala es que a los solos efectos de facilitar la constitución ex novo de una adopción del makful en España, la kafala será considerada "por equiparación» como un acogimiento familiar «español» o como una tutela «española». Ello se explica por la ubicación de este precepto en una Ley sobre «adopción internacional». A partir de aquí, y más allá de los límites de este estudio, se suscita la pregunta de los efectos jurídicos que una kafala puede surtir en España al margen de toda equiparación con una tutela o acogimiento familiar español para facilitar la posterior adopción española. La respuesta exigiría un cambio en la orientación que hasta ahora se ha dado a este tema. Tal y como ha expuesto M. ${ }^{a}$ P. Diago Diago, parece más indicado proceder a una "calificación por la función» de la kafala, lo que permite equiparar la kafala con diversas instituciones jurídicas españolas según sea la función jurídica desarrollada por la primera en el caso concreto (véase Diago Diago, M. ${ }^{\text {a }}$ P., "La "Kafala" islámica en España», $C D T$, 2010, vol. 2, núm. 1, pp. 140-164).

El tercer estudio es el escrito por A. Quiñones Escámez (QuiÑones EscámEz, A., «Protección del menor venido a España en kafala: acogimiento con tutela dativa y, en su caso, adopción», pp. 157197). Se trata de un trabajo bien pertrechado de armas jurisprudenciales y es aquí donde radica su mérito principal, en la lectura crítica de la jurisprudencia española en materia de kafala. En particular, llama la atención la reprobación que merece a la autora la ya famosa STSJ de Madrid de 31 de enero de 2008 (kafala marroquí). En dicho pronunciamiento, el tribunal afirma que debe equiparar $k a$ fala y adopción a efectos de pensión de orfandad porque la adopción no podía constituirse con arreglo a la Ley personal del menor. Esta conclusión es errónea, porque naturalmente, la constitución de la adopción sí que era posible. El tribunal dictó su sentencia con total desprecio de las normas legales vigentes y dicha glissade debe ser justamente censurada, como muy bien hace la autora (véase en p. 170 in fine) y como han denunciado también otros autores (Calvo Caravaca, A.-L., y Carrascosa González, J., "Adopción internacional», en Calvo CaravaCA, A.-L., y Carrascosa González, J. (dirs.), Derecho internacional privado, vol. II, 10. ${ }^{\text {e ed., }}$ Granada, Comares, 2009, p. 272). Más fino hila la jurisprudencia francesa en estas lides [véase, por ejemplo, Sentencia Cour Cass. (Francia), de 11 de junio de 2009]. La autora maneja abundantes datos de Derecho internacional privado comparado para buscar soluciones jurídicas a la inserción de la kafala y sus efectos legales en los países europeos, lo que sin duda, enriquece la perspectiva de análisis del lector. A. Quiñones Escámez presta especial atención, con un cuidado arsenal metodológico que tanto se echa de menos en otros estudios sobre muticulturalidad jurídica, a la prohibición de adoptar menores que rige en ciertos Derechos islámicos y al cambio que experimentó la Ley 54/2007 de adopción internacional durante su tramitación parlamentaria sobre este particular. En este punto, la autora aborda el debate, bien nutrido de opiniones en la doctrina española, relativo a la posibilidad de utilizar la kafala como una herramienta legal para extraer el menor de su país de origen con la finalidad última de constituir una adopción en España. La práctica judicial española está llamada, en el próximo futuro, a suministrar criterios sobre esta problemática, lo que a su vez, alimentará el debate doctrinal y contribuirá a dotar de nuevos perfiles la todavía jeunesse dorée de la Ley 54/2007 de adopción internacional. No está de más recordar que el Dictamen 1/2009 de la Fiscalía General del Estado sobre la posibilidad de que la kafala sea equiparada a la tutela o al acogimiento familiar a efectos de permitir proponer una posterior adopción "de tipo español», señala en su conclusión cuarta que la posible prohibición o desconocimiento por parte del De- 
recho del país de origen del menor de la institución de la adopción no será óbice a la constitución de ésta. La polémica está servida, así, en bandeja de plata.

En suma, se trata de una obra de indudable interés para los estudiosos del Derecho islámico y del Derecho internacional privado, de agradable lectura, bien fundamentada y con notable rigor metodológico. Una obra que presenta el mérito de conjugar con elegancia tres ángulos imprescindibles en el estudio de la kafala desde el prisma del Derecho internacional privado: el análisis del Derecho material marroquí relativo a la kafala, las reacciones jurisprudenciales españolas y de otros países frente a dicha institución, y un valioso sentido práctico.

Javier CARRASCOSA Universidad de Murcia

\section{SEIBERT-FoHR, A., Prosecuting serious human rights violations, Oxford Univer- sity Press, 2009.}

Como fielmente refleja su propio título, esta obra tiene por objeto la persecución de las violaciones graves de los derechos humanos, ofreciendo un detallado estudio de las obligaciones internacionales (tanto de naturaleza convencional como consuetudinaria) que imponen a los Estados la persecución de los perpetradores de violaciones graves de los derechos humanos. La cuestión de fondo objeto de este libro es la determinación de la existencia o no de una obligación internacional a cargo de los Estados que va más allá de la propia obligación de investigación de las violaciones graves de los derechos humanos y que exigiría a los Estados perseguir a los perpetradores de tales violaciones. Esta determinación la efectúa la autora (que es Directora del Grupo de Investigación Minerva, del Max-Planck Institut für ausländisches öffentliches Recht und Völkerrecht de Heidelberg, Alemania) a partir del examen de una pluralidad de tratados internacionales de derechos humanos de ámbito general o universal y de dos de ámbito regional (en este caso, sólo el Convenio Europeo de Derechos Humanos de 1950 y la Convención Americana de Derechos Humanos de 1969).

Es en este contexto que la autora analiza también la conformidad o no con el Derecho internacional de medidas estatales que consagran la impunidad, como es el caso de las leyes de amnistía, leyes de punto final, etcétera.

El libro está estructurado en torno a ocho capítulos siendo el capítulo 1 de carácter introductorio. Señala la autora que los capítulos 2 (la persecución en el marco del Pacto Internacional de Derechos Civiles y Políticos de 1966), 3 (la persecución en el marco de la Convención Americana de Derechos Humanos de 1969) y 4 (la persecución en el marco del Convenio Europeo de Derechos Humanos de 1950) conforman la primera parte del trabajo; parte que considera la obligación de perseguir como una obligación no escrita existente en el ámbito de la protección de los derechos humanos. El objetivo de la misma es explicar el modo en el que los tribunales competentes y los órganos de control previstos por los tratados de derechos humanos han desarrollado su doctrina en orden a configurar una obligación convencional de persecución de las violaciones graves de los derechos humanos.

El capítulo 5 se ocupa de los tratados internacionales de derechos humanos de ámbito general o universal que establecen expresamente la obligación de perseguir: la Convención para la Prevención y Castigo del Crimen de Genocidio (1948); la Convención de la ONU contra la Tortura (1984); la Convención sobre la Esclavitud 
(1926), el Convenio para la Represión de la Trata y de la Explotación de la Prostitución Ajena (1949); la Convención Internacional para la Represión y Castigo del Crimen de Apartheid (1973); la Convención sobre la Imprescriptibilidad de los Crímenes de Guerra y de los Crímenes de Lesa Humanidad (1968); la Convención Internacional sobre la Eliminación de todas las formas de Discriminación Racial (1965); la Convención Internacional para la Protección de todas las Personas contra las Desapariciones forzadas (2005).

El capítulo 6 (conceptualizando el deber de perseguir en el marco de los tratados sobre derechos humanos) compara y evalúa los diferentes razonamientos jurídicos empleados para fundamentar la persecución de las violaciones graves de los derechos humanos y realiza sugerencias para desarrollos jurisprudenciales posteriores. En este sentido, trata de guiar esa futura conceptualización centrándose en el papel específico que la persecución puede jugar en el Derecho Internacional de los derechos humanos.

El capítulo 7 cambia de perspectiva para examinar si el Derecho internacional consuetudinario permite fundamentar la existencia de un deber de perseguir las violaciones graves de los derechos humanos. En este contexto se realizan referencias tanto al Derecho internacional penal como al emergente concepto de responsabilidad del Estado por violación de los derechos humanos.

El capítulo 8 (Conclusiones) evalúa la convergencia existente entre el Derecho internacional de los derechos humanos y el Derecho internacional penal, considerando el papel que los derechos humanos deberían jugar en el concepto emergente de justicia global.

El libro concluye con la advertencia de no asumir rápidamente una obligación indiscutible a cargo de los Estados de castigar las violaciones de los derechos humanos. Pero, también, con la advertencia de la necesidad de ser conscientes de las razones que se invocan para exigir ese castigo. En opinión de la autora, el Derecho internacional de los derechos humanos no es un Derecho de retribución por lo que no debe ser utilizado para ampliar el alcance del Derecho internacional penal sin una firme base jurídica. Y concluye: «lo que en un primer momento parece una laguna en el Derecho de los derechos humanos, esto es, la ausencia de una obligación explícita de perseguir todas las violaciones graves de los derechos humanos, en un análisis cuidadoso se revela como necesario en orden a tratar adecuadamente situaciones que requieren respuestas específicas».

En definitiva, una obra rigurosa, muy bien documentada y muy interesante que aborda una cuestión hasta el momento no tratada (al menos que yo sepa) por la doctrina española de Derecho internacional público y que, sin embargo, resulta necesaria tanto en el marco del Derecho internacional de los derechos humanos como en el del Derecho internacional penal. En especial, en el emergente campo de investigación relativo a las víctimas en el Derecho internacional.

Carlos Fernández de CaSADEvante ROMANI

Universidad Rey Juan Carlos 